\title{
Control Parameters of Magnitude-Seismic Moment Correlation for the Crustal Earthquakes
}

\author{
Ernes Mamyrov \\ Institute of Seismology of the National Academy of Sciences of the Kyrgyz Republic, Bishkek, Kyrgyz Republic \\ Email: nernesova@gmail.com; kis@elcat.kg
}

Received June 12, 2013; revised July 19, 2013; accepted August 8, 2013

Copyright (C) 2013 Ernes Mamyrov. This is an open access article distributed under the Creative Commons Attribution License, which permits unrestricted use, distribution, and reproduction in any medium, provided the original work is properly cited.

\begin{abstract}
In connection with conversion from energy class $K_{R}\left(K_{R}=\log _{10} E_{R}\right.$, where $E_{R}$ - seismic energy, $\left.\mathrm{J}\right)$ to the universal magnitude estimation of the Tien Shan crustal earthquakes the development of the self-coordinated correlation of the magnitudes $\left(m_{b}, M_{L}, M_{s}\right)$ and $K_{R}$ with the seismic moment $M_{0}$ as the base scale became necessary. To this purpose, the first attempt to develop functional correlations in the magnitude - seismic moment system subject to the previous studies has been done. It is assumed that in the expression $M\left(m_{b}, M_{L}, M_{s}\right)=k_{i}+z_{i} \log _{10} M_{0}$, the coefficients $k_{i}$ and $z_{i}$ are controlled by the parameters of ratio $\log t_{0}=a_{t}+b_{t} \log _{10} M_{0}$ (where $t_{b}=f_{0}^{-1} ; f_{0}$-corner frequency, Brune, 1970, $\left.1971 ; M_{0}, \mathrm{~N} \cdot \mathrm{m}\right)$. According to the new theoretical predictions common functional correlation of the advanced magnitudes $M_{m}\left(m_{b m}=m_{b}, M_{L m}=M_{L}, M_{S m}=M_{S}\right)$ from $\log _{10} M_{0}, \log _{10} t_{0}$ and the elastic properties $\left(C_{i}\right)$ can be presented as $M_{m}=d_{i} \log _{10} M_{0}-2 \log _{10} t_{0}+C_{i}$, where $z_{i}=d_{i}-2 b_{t}$, and $k_{i}=C_{i}-2 a_{t}$, for the averaged elastic properties of the Earth's crust for the $m_{b m}$ the coefficients $C_{i}=-11.30$ and $d_{i}=1.0$, for $M_{L m}: C_{i}=-14.12, d_{i}=7 / 6$; for $M_{S m}$ : $C_{i}=-16.95$ and $d_{i}=4 / 3$. For the Tien Shan earthquakes (1960-2012 years) it was obtained that $\log _{10} t_{0}=0.22 \log _{10} M_{0}-3.45$, and on the basis of the above expressions we received that $M_{S m}=1.59 m_{b m}-3.06$. According to the instrumental data the correlation $M_{s}=1.57 m_{b}-3.05$ was determined. Some other examples of comparison of the calculated and observed magnitude - seismic moment ratios for earthquakes of California, the Kuril Islands, Japan, Sumatra and South America are presented.
\end{abstract}

Keywords: Magnitude; Seismic Moment; Energy Class; Earthquakes; Frequency

\section{Introduction}

In world practice, seismological research in assessing the scale of earthquakes magnitude scale of Gutenberg and Richter [1-3] is fundamental. In the countries of the former Soviet Union has been used scale independent energy class $K_{R}$, defined as the logarithm of the seismic energy $E_{R}$, highlighted by an earthquake, measured in joules $\left(K_{R}=\log _{10} E_{R}\right.$, [4-6]).

For crustal earthquakes Tien Shan when considering the transition to magnitude scale was necessary to develop a self-consistent system of quantitative relationships that justify numerous empirical relationships bodywave magnitude $m_{b}$, local magnitude on surface waves $M_{L}$, surface wave magnitude for $M_{S}$ and $K_{R}$ from seismic moment $M_{0}(\mathrm{~N} \cdot \mathrm{m})$, as the reference scale. In connection with the above purpose is to study the quantitative relationships $m_{b}, M_{L}, M_{S}$ and energy of seismic radiation $E_{S} \mathrm{c}$
$M_{0}$ based on the following findings:

1) proportional magnitudes and the maximum amplitude of seismic vibrations [1-3];

2) the statistical dependencies of the average magnitude of displacement along the fault $u$ [7-12] and $u$ functional relationship with the seismic moment, the shear modulus $\mu$ and the gap area $S$ [13-14];

3) functional relationship corner period $t_{6}=f_{0}^{-1} \mathrm{~s}$ with $M_{0}$, the source radius $r_{0}$, speed $\mathrm{S}$ - wave $v_{S}$ and static stress drop $\Delta \sigma[15,16]$, as well as the similarity of the angular frequency $f_{0}$ with a fundamental frequency of the acoustic Debye [17] $f_{D}$, depending on the amount of source and the elastic properties of the geophysical medium [18].

Our further quantitative construction is based on the following empirical relationship Gutenberg and Richter $[3,12]$ : 


$$
\begin{aligned}
& \log _{10} E_{G R}=K_{G R}=4.8+1.5 M_{S} \\
& M_{S}=1.59 m_{b}-3.97 \\
& \log _{10} t_{0}=0.32 M_{L}-1.4
\end{aligned}
$$

where $E_{G R}$ - seismic energy according to Getenberg and Richter, $\mathrm{J} ; t_{0}$-fluctuations with a maximum duration of vibration speed $A / T$ in the near field ( $A$-amplitude, $T$ period), s.

Use the following generalization of Soviet seismologists, which were introduced scale energy class $K_{R}$ [5], the magnitude of surface waves $M_{L H}$ (IC device) and body waves $m_{P V}$ on device SCM [4,9]:

$$
\begin{aligned}
& \log _{10} E_{R}=K_{R}=4.0+1.8 M_{L H} \\
& \log _{10} t_{m}=0.35 M_{L H}-1.4 \\
& m_{b}=5.53+0.45\left(K_{R}-14\right) \\
& m_{P V}=0.35 \log _{10} M_{0}-2.75
\end{aligned}
$$

where $E_{R}$ - seismic energy according to [5], in $\mathrm{J} ; K_{R}=$ $\log _{10} E_{R} ; t_{m}$-increase the maximum duration of the seismic intensity in the near field, in sec.

The basis of the theoretical constructs are the following functional relations $[10,13,15,16,19]$ :

$$
\begin{aligned}
& M_{0}=\mu \cdot S \cdot u=(16 / 7) \Delta \sigma \cdot r_{0}^{3} \\
& =(16 / 7)(2.35 / 2 \pi)^{3} \Delta \sigma \cdot V_{S}^{3} \cdot t_{b} \\
& E_{S K}=(\Delta \sigma / 2 \mu) M_{0} \\
& r_{0}=(2.34 / 2 \pi) \cdot v_{S} \cdot t_{b} \\
& M_{W}=(2 / 36) \log _{10} M_{0}-6.07
\end{aligned}
$$

where $r_{0}$-radius of the source, in $\mathrm{M} ; \Delta \sigma$-static seismic stress drop, in $\mathrm{Pa} ; t_{b}$ - corner period, $\mathrm{s} ; M_{W}$-moment magnitude; $\left(E_{S K}\right.$, in $\mathrm{J} ; M_{0}$, in $\mathrm{N} \cdot \mathrm{m}$; $u$ in $\mathrm{m} ; v_{S}$ in $\left.\mathrm{m} / \mathrm{s}\right)$; for the constructions made $t_{0}=t_{b}=t_{m}$.

Many generalizations proved that for a wide range of changes $\log _{10} M_{0}$ or $M_{W}$ empirical correlations magnitude $m_{b}, M_{L}$ and $M_{S}$ from $M_{0}$ are non-linear, as in Equation (8), as a function of $M_{0} \sim f\left(t_{0}^{n}\right)$ value of $n$ varies from 3 to 6 , and is increase $\Delta \sigma[7,12,20-24]$.

However, for individual intervals $M_{0}$ or $M_{W}$ communication between magnitudes relationships and dependencies of the magnitude $\log _{10} M_{0}$ can be represented as linear relationships.

\section{Justification Relations Magnitude-Seismic Moment}

Based on the original definition of magnitude on Richter [25], under which the numerical value of the earthquake magnitude is proportional to the logarithm of the maximum oscillation decimal $B_{m}$, expressed in microns $\left(10^{-6} \mathrm{M}\right)$, it is assumed that an upgraded body-wave magnitude $m_{b m}$ (equivalent $m_{b}, m_{P V}$ ) is (considering doubling $\sigma_{m}$ on the ground at the focus):

$$
m_{b m}=\log _{10} \theta_{m}+6.3=\log _{10} u+6
$$

If $S=\pi r_{0}^{2}$ in (8) on the basis Equations (9) and (10) and Equation (12) value $m_{b m}$ equal $\left(M_{0}, \mathrm{~N} \cdot \mathrm{m} ; t_{b}, \mathrm{~s} ; \mu, \mathrm{Pa}\right.$; $\left.v_{s}, \mathrm{~m} / \mathrm{s}\right)$ :

$$
m_{b m}=C_{1}+\log _{10} M_{0}-2 \log _{10} t_{0}
$$

where $C_{1}=\log _{10}\left[2 \pi(2.34)^{-2} \cdot \mu^{-1} \cdot v_{S}^{-2}\right]+6.3$, value $C_{1}$ determines the springiness of the geophysical environment at $m_{b \mathrm{~m}}$.

Based on generalizations Christensen [26,27] for the crust taken: average density

$\rho=2830 \mathrm{~kg} / \mathrm{m}^{3}, v_{S}=3600 \mathrm{~m} / \mathrm{s}$ and

$\mu=\rho \cdot v_{S}^{2}=36.7 \mathrm{GPa}$ in what follows, these quantities $\rho, v_{s}$ and $\mu$ taken as the standard.

When these elastic parameters of the geophysical medium expression Equation (13) is transformed to the following form:

$$
\begin{aligned}
& m_{b m}=\log _{10} M_{0}-2 \log _{10} t_{0}-11.30 \\
& =1 / 3 \log _{10} M_{0}+2 / 3 \log _{10} \Delta \sigma-4.80
\end{aligned}
$$

Seismic energy radiation $E_{S K}$ by Kanamori [19], based on Equations (8) and (9) and Equation (13) is:

$$
\begin{aligned}
& \log _{10} E_{S K}=K_{S K}=C_{2}+2 \log _{10} M_{0}-3 \log _{10} t_{0} \\
& =C_{2}-C_{1}+2 m_{b m}+\log _{10} t_{0}
\end{aligned}
$$

where $C_{2}=\log _{10}\left[7 \cdot \pi_{3} \cdot 4^{-1} \cdot(2.34)^{-3} \cdot \mu^{-1} \cdot v_{S}^{-3}\right]$.

Taken for the elastic parameters and subject [19]. $E_{S K} / M_{0}=\Delta \sigma / 2 \mu=5 \times 10^{-5}$ obtain: $\Delta \sigma=3.67 \mathrm{MPa}$ and 36.7 bar and the expression Equation (8) can be rewritten in a simple form $\log _{10} t_{0}=1 / 3 \log _{10} M_{0}-5.43$, then Equation (15) simplifies to:

$$
\begin{aligned}
& K_{S K}=2 \log _{10} M_{0}-3 \log _{10} t_{0}-20.61 \\
& =1.5 M_{W}+4.8=3 m_{b m}-3
\end{aligned}
$$

On the basis of Equations (13)-(16), reflecting the functional relationship of $E_{S K}$ from $M_{0}, t_{0}, m_{b m}$ and $\mu$ at $E_{G R}=E_{S K}$ introduced upgraded the magnitude of surface waves $M_{S m}$ (equivalent of $M_{S}, M_{W}$ ), while maintaining that the formula Equation (1) Gutenberg and Richter [2,3], with Equation (9), Equations (15) and (16) will be:

$$
\begin{aligned}
& M_{S m}=(4 / 3) \log _{10} M_{0}-2 \log _{10} t_{0}+C_{S} \\
& =2 / 3\left(\log _{10} M_{0}+\log _{10} \Delta \sigma\right)-10.45=(2 / 3) K_{S K}-3.2
\end{aligned}
$$

where $C_{S}=(2 / 3) C_{2}-3.2$.

Taken for $\rho$ and $v_{S} C_{S}$ value in Equation (17) is equal to $C_{S}=-16.95$, and for the special case of $\Delta \sigma=3.67 \mathrm{MPa}$ = const and $E_{S K} / M_{0}=5 \times 10^{-5}$ equality: $M_{S m}=M_{W}$.

We also introduce a modernized local magnitude on 
surface waves $M_{L m}$ —equivalent $M_{L}$ [18,28], functionally interconnected with $\log _{10} M_{0}, \log t_{0}, K_{S K}, m_{b m}$ and $M_{S m}$ :

$$
\begin{aligned}
& M_{L m}=0.5\left(m_{b m}+M_{S m}\right)=(7 / 6) \log _{10} M_{0}-2 \log t_{0}+C_{L} \\
& =0.5 \log _{10} M_{0}+2 / 3 \log _{10} \Delta \sigma-7.62
\end{aligned}
$$

where $C_{L}=0.5\left(C_{1}+C_{S}\right)$ : for standard values $\rho$ and $v_{S}$ value $C_{L}$ is equal: $C_{L}=-14.12$.

Accepted values for $\rho$ and $v_{S}$ by Equation (8) and Equation (9) the following relationship:

$$
\log _{10} \Delta \sigma=\log _{10} M_{0}-3 \log _{10} t_{0}-9.74
$$

With the standard values $\rho, v_{S}$ and $\Delta \sigma=3.67 \mathrm{MPa}$, based on Equation (14) and Equation (17) we obtain the following theoretical relation:

$$
m_{b m}=2.60+0.5 M_{S m}
$$

which is within the accuracy of the definitions of the same magnitude satisfactory empirical relation refined body wave magnitude $\hat{m}_{b}$ of $M_{W}$ for large earthquakes $[19,29]\left(m_{b} \geq 6\right)$ :

$$
\hat{m}_{b}=2.70+0.53 M_{W}
$$

which were used $\hat{m}_{b}$ to calculate the true maximum oscillation amplitude $A_{g}$, taken from seismograms; $A_{g} \sim f\left(M_{0}^{0.35}\right)$.

Here it should be emphasized that at a constant value of $\Delta \sigma$ Equation (12) and Equation (14) the value of the maximum amplitude $\theta_{\mathrm{m}}$ is proportional to $\mathrm{M}_{0}^{1 / 3}$ or ${B_{m}}_{m} \sim f\left(M_{0}^{0.33}\right)$, that closely coincides with $A_{g} \sim f\left(M_{0}^{0.35}\right)$ on $[19,29]$.

In the sequel will be shown $m_{b m} \approx \hat{m}_{b}$.

Equation (20) agrees satisfactorily with other empirical relationship [9]

$$
\left(m_{P V}=m_{b}+0.18\right) \text { : }
$$

$$
m_{P V}=2.86+0.525 M_{W}
$$

The above quantitative ratios indicate that between modernized magnitudes

$M_{m}\left(m_{b m}, M_{L m}, M_{S m}\right)$ and $\log _{10} M_{0}$ may exist linear functional relationship of the form:

$$
M_{m}\left(m_{b m}, M_{L m}, M_{S m}\right)=k_{i}+z_{i} \log _{10} M_{0}
$$

in which the coefficients $k_{i}$ and $z_{i}$ at the control parameter $a_{t}$ and $b_{t}$ in the ratio:

$$
\log _{10} t_{0}=a_{t}+b_{t} \log _{10} M_{0}
$$

where $\Delta \sigma=$ const $=3.67 \mathrm{MPa} b_{t}=1 / 3=$ const and $a_{t}=$ -5.43 , but for other cases $b_{t}$ is not a constant.

In view of Equations (23) and (24) correlations Equations (14), (17) and Equation (18) for $m_{b m}, M_{S m}$ and $M_{L m}$ (standard values $\rho$ and $v_{S}$ ) can be written as follows:

$$
m_{b m}=\left(1-2 b_{t}\right) \log _{10} M_{0}-2 a_{t}-11.30
$$

$$
\begin{aligned}
& M_{S m}=\left(4 / 3-2 b_{t}\right) \log _{10} M_{0}-2 a_{t}-16.95 \\
& M_{L m}=\left(7 / 6-2 b_{t}\right) \log _{10} M_{0}-2 a_{t}-14.12
\end{aligned}
$$

which provide a self-consistent system of semi empirical inter magnitude dependencies. For example, the dependence of $m_{6 m}$ from $M_{S m}$ based on Equations (25) and (26) can be expressed as:

$$
m_{b m}=\frac{1-2 b_{t}}{4 / 3-2 b_{t}}\left(M_{S m}+2 a_{t}+16.95\right)-2 a_{t}-11.30
$$

which is $b_{t}=0.33$ and $a_{t}=-5.43$ ransformed into simple formula Equation (20).

\section{Discussion of Empirical and Theoretical Relations Magnitude-Seismic Moment}

Local magnitude-seismic moment. Since the value of the local magnitude is directly related to the maximum oscillation amplitude of the surface waves and the first inter magnitude connections [2,3] have been developed for California earthquakes, relations $M_{L}-\log t_{0} M_{0}$ consider according to Thatcher and Hanks [30] in this region $\left(2 \leq M_{L} \leq 6.8\right)$.

For this region, the authors have taken $\rho=2700 \mathrm{~kg} / \mathrm{m}^{3}$ and $v_{S}=3200 \mathrm{~m} / \mathrm{s}$, and by (13) and (17) a constant values will be: $C_{1}=-11.09, C_{S}=-16.5, C_{L}=-13.72$. With known $\rho, v_{s}, \Delta \sigma / 2 \mu=5 \times 10^{-5}$ between $\log _{10} t_{0}$ and $\log _{10} M_{0}$ would expect the following relationship: $\log _{10} t_{0}=(1 / 3) \log _{10} M_{0}-5.34$, but the instrumental data obtained (Figure 1, $N$ - the number of data, $r$ - correlation coefficient):

$$
\log _{10} t_{0}=0.25( \pm 0.03) \log _{10} M_{0}-3.90( \pm 0.43)
$$

i.e. in accordance with (19) with increasing values of $M_{0} \log _{10} \Delta \sigma$ increases:

$\log _{10} \Delta \sigma=0.25 \log _{10} M_{0}+2.12$. Therefore, for the considered data characteristic dependence $M_{0} \sim f\left(t_{0}^{4}\right)$, said Nuttli [12] for mid-plate earthquakes.

If true theoretical Equations (13), (17) and (18), then

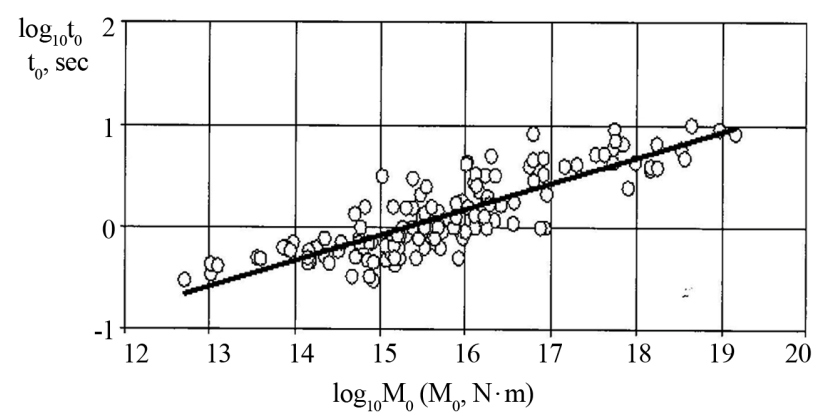

Figure 1. Correlation of $\log _{10} t_{0}$ from $\log _{10} M_{0}$ for Southern California earthquakes according to Thatcher and Hanks [30] $\left(\log _{10} t_{0}=0.25( \pm 0.03) \log _{10} M_{0}-3.90( \pm 0.43), N=138, r\right.$ $=\mathbf{0 . 8 4})$. 
Equation (29) and the relationship between $M_{L m}$ and $\log _{10} t_{0}$ is given by:

$$
\log _{10} t_{0}=0.37 M_{L m}-1.68
$$

which is in good agreement with the expression (3) Gutenberg and Richter [2] and Equation (5) Soviet seismologists [31] which allows to consider $t_{0}=t_{6}=t_{m}$.

In Figure 2 shows the correlation $\log _{10} t_{0}$ and $M_{L}$ according to Thatcher [30], which also shows the relationship Equation (3) and Equation (30). The presented data show that the semi-empirical formula Equation (30) is in good agreement with generalizations instrumental data (Figure 2). It should also be noted that the $M_{L}=M_{L m}$ based on Equation (3) Gutenberg and Richter [2], and
Equation (18) can be obtained

$$
\log _{10} t_{0}=0.23 \log _{10} M_{0}-3.53
$$

which is in satisfactory agreement with the expression (29).

In Figure 3 in the range of $0.5 \leq M_{L} \leq 6.8$ shows the correlation ratio $M_{L m}$ of $M_{L}$ for Southern California earthquakes [30], South-West Germany [32] and Central Japan [33]. In calculations $M_{L m}$ by Equation (18) for the earthquakes in these regions were considered elastic parameters of the geophysical medium according to these authors. The statistical data confirm the validity of our assumptions on the possible equality $M_{L}$ and $M_{L m}$ (Figure 3).

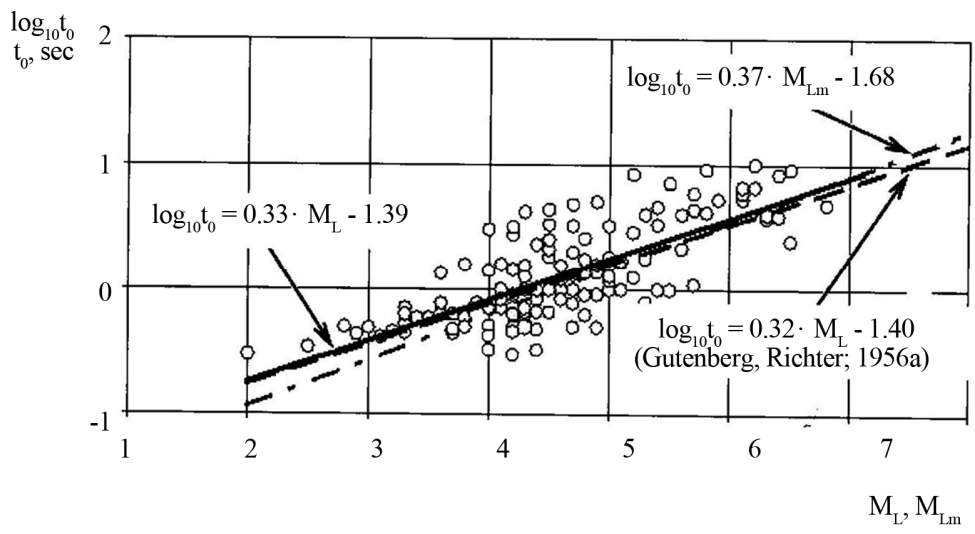

Figure 2. Correlation of $\log _{10} t_{0}$ from $M_{L}$ for Southern California earthquakes according to Thatcher and Hanks [30], full line: $\log _{10} t_{0}=0.33( \pm 0.05) M_{L}-1.39( \pm 0.23), N=138, r=0.84$. Dashed line- $\log _{10} t_{0}=0.32 M_{L}-1.40$ by Gutenberg and Richter (1956a); dot-dash line-dependence $\log _{10} t_{0}$ from $M_{L m}$, obtained from correlation $\log _{10} t_{0}$ from $\log _{10} M_{0}$ (Figure 1).

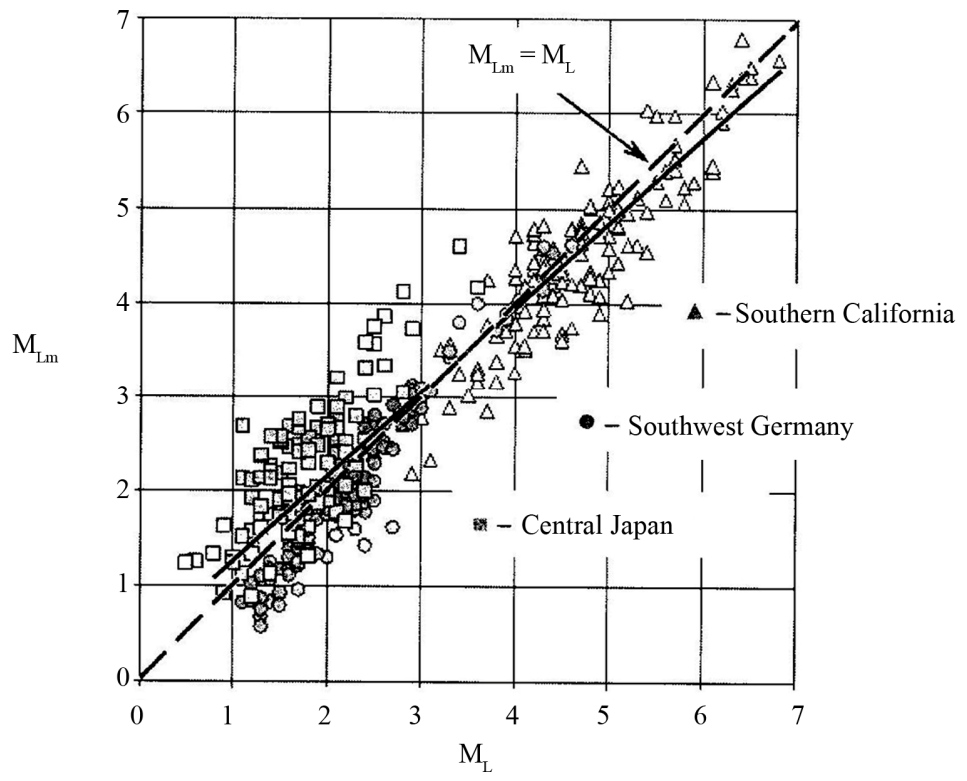

Figure 3. The ratio of calculated $M_{L m}$ and instrumental $M_{L}$ for Southern California earthquakes by Thatcher and Hanks [30], South-West Germany (Scherbaum et al. 1983) and Cental Japan (Jin et al., 2000). $M_{L m}=0.9( \pm 0.03) M_{L}-0.28( \pm 0.05), N=$ 384, $r=0.94$; dashed line $M_{L m}=M_{L}$. 
From numerous publications on nonlinear relations $\log _{10} M_{0}-M_{L}$ acceptability of new assumptions considered on the basis of Hasegawa [34] for earthquakes in Eastern Canada. In the range $0<M_{L} \leq 6.3$ are two of the interval $0<M_{L} \leq 3.9$ and $3.9 \leq M_{L} \leq 6.3$, which have different dependencies on $\log _{10} t_{0}$ of $M_{L}$ and $\log _{10} M_{0}$ from $M_{L}$ [34].

For the first group of small earthquakes characterized by the following relationship $\left(10^{5}<\Delta \sigma<10^{6} \mathrm{~Pa}\right)$ : $\log _{10} t_{0}=0.18 \log _{10} M_{0}-3.14$, but for another group $\left(10^{6}\right.$ $\left.\leq \Delta \sigma<5 \times 10^{6} \mathrm{~Pa}\right): \log _{10} t_{0}=0.28 \log _{10} M_{0}-4.54$.

On the basis of these empirical formulas for Equation (18) and Equation (24) with $C_{L}=-14.21\left(\rho=2800 \mathrm{~kg} / \mathrm{m}^{3}\right.$ and $v_{s}=3800 \mathrm{~m} / \mathrm{s}$ ) Figures 4 and $\mathbf{5}$ shows the calculated dependences of $\log _{10} t_{0}$ from $M_{L m}$ and $\log _{10} M_{0}$ from $M_{L m}$, which in satisfactory agreement with the relations $\log _{10} t_{0}-$ $M_{L}$ and $\log _{10} M_{0}-M_{L}$ (Figures 4 and 5) by Hasegawa [34].

Finally, for the Southern California Earthquake Equation (18) and Equation (29) we can obtain the following relationship: $M_{L m}=0.67 \log _{10} M_{0}-5.92$, which coin- cides with the ratio of [30]:

$$
M_{L}=0.67 \log _{10} M_{0}-6.0
$$

According to Equations (23) and (24) and Equation (27) if $b_{t}=0.25$ we get $z_{i}=7 / 6-2 b_{t}=0.67$, which indicates the acceptability of the proposed relations.

From Equation (32) it follows that $b_{t}=0.25$ in Equation (24) the values of $M_{L}$ and $M_{L m}$ magnitude $M_{W}$ corresponds to Equation (11). Probably, the presence of the form Equation (29) between $\log _{10} t_{0}$ and $\log _{10} M_{0}$ explains equality $M_{L}=M_{W}$ for earthquakes with $M_{W} \leq 7.0$ NorthWest Europe [35], New Zealand [36], western Canada [37] and about Taiwan [38].

\subsection{Ratio $m_{b}-\log _{10} M_{0}$ : Design and Data Tools}

As in the case of search based $M_{L}-\log _{10} M_{0}$, for bodywave magnitude $m_{b}$ consider empirical relationships

According to Zapolsky [31], Gutenberg [1], specifically examining the relationship between the energy of focal radiation and earthquake magnitude according to

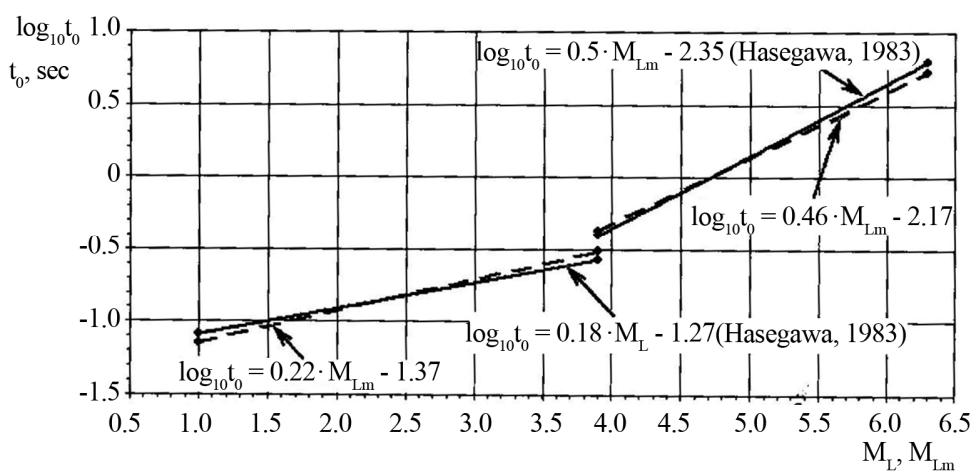

Figure 4. Correlation $\log _{10} t_{0}$ from $M_{L}$ (full line-Hasegawa [34] and from calculated $M_{L m}$ (dashed line, see the text) for East Canada earthquakes.

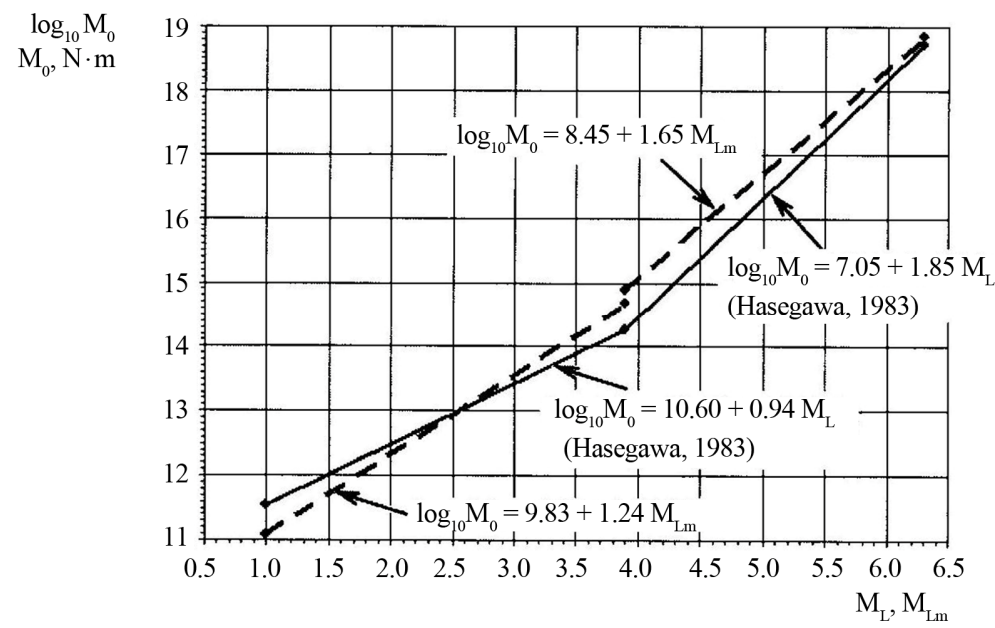

Figure 5. Correlation $\log _{10} M_{0}$ from $M_{L}$ (full line-Hasegawa [34] and from calculated $M_{L m}$ (dashed line, see the text) for East Canada earthquakes. 
the observations in the epicentral area, showed that the duration $t_{0}$, determine the energy of the oscillations with the maximum intensity depends strongly on the magnitude and 2.5-fold increases with increasing magnitude of $m_{b}$ on unit [31].

$$
\log _{10} t_{0}=0.4 m_{b}-1.9
$$

A little-known empirical formula Equation (32) Gutenberg [1] is a key for further generalizations of our constructions on relations $m_{b}-\log _{10} M_{0}$, and $m_{b}-M_{S}$

On the basis of (13) and (29) with $C_{1}=-11.09$, we can get:

$$
\log _{10} t_{0}=0.5 m_{b}-2.26
$$

Substitution $\log _{10} t_{0}=0.23 \log _{10} M_{0}-3.53$ in Equation (31) into (13) leads to the following formula:

$$
\log _{10} t_{0}=0.42 m_{b}-1.84
$$

which is in good agreement with (33) provided $m_{b}=m_{b m}$.

Graphic expressions Equations (33)-(35) are shown in Figure 6, from which it can be assumed about the close convergence of these relations and the possible equality $m_{b}=m_{b m}$ (Figure 6). At equality $m_{b}=m_{b} m$-based Equations (13) and (33) for the standard $\rho$ and $v_{S}$ can obtain the expression:

$$
\log _{10} t_{0}=0.22 \log _{10} M_{0}-3.57
$$

which is in good agreement with Equations (29) and (31), which may indicate the consistency of our constructions relating $m_{b}, m_{b m}, M_{L}, M_{L m}$ and $\log _{10} t_{0}$ with $\log _{10} M_{0}$ for earthquakes in California, despite the fact that the conclusions are based on statistical formulas in which the correlation coefficients are not equal to unity $(r=0.75$ $0.90)$

If we use the Equation (36), on the basis of Equation (24) with $b_{t}=0.22$ and Equations (25) and (26) for the

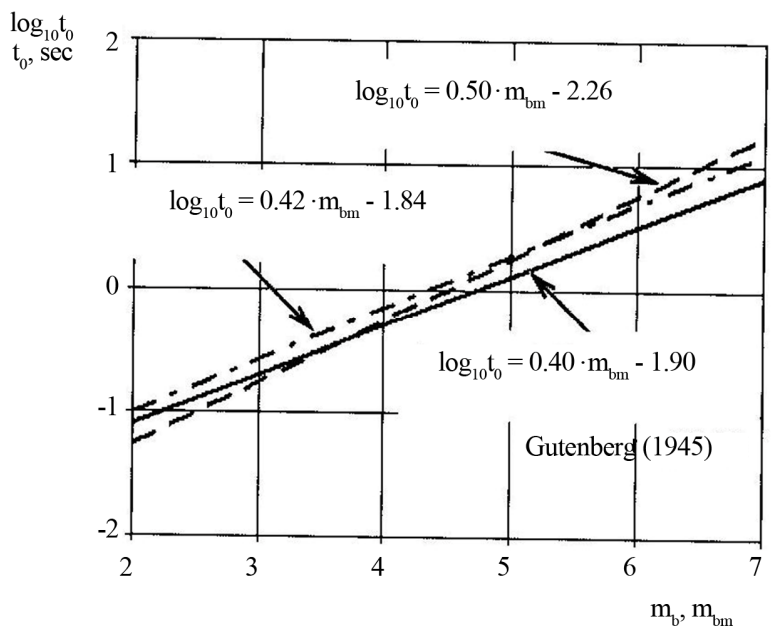

Figure 6. Correlation $\log _{10} t_{0}$ and $m_{b}$ (full line), $\log _{10} t_{0}$ and $m_{b m}$ (dashed line, see the text). standard values $\rho$ and $v_{S}, M_{S m}$ dependence on $m_{b m}$ can be expressed as:

$$
M_{S m}=1.59 m_{b m}-3.20
$$

which almost corresponds to the classical formula Equation (2) Gutenberg and Richter (1956в) and for which the equality $M_{S m}=m_{b m}$ complied with $M_{s m}=5.40$, which coincides closely with generalizations Chen [7], Gusev [9], Nuttli [12] and Utsu [24].

In Figure 7 shows the correlation of $\log _{10} t_{0}$ from $\log _{10} M_{0}$ for earthquakes in the world (1981-1991) by the Catalogue Choy [39], for which the value of $t_{0}$ was taken from the Global CMT Catalogue. The ratio of $\log _{10} t_{0}$ from $\log _{10} M_{0}$ for these data is given by (Figure 7):

$$
\log _{0} t_{0}=0.30( \pm 0.01) \log _{10} M_{0}-4.88( \pm 0.01)
$$

for which the range $17 \leq \log _{10} M_{0} \leq 21$ value of $\log _{10} \Delta \sigma$ by Equation (19) increases from 6.60 to 7.10 .

Substituting (38) in (13) leads to $\left(C_{1}=-11.30\right)$ :

$$
m_{b m}=0.40 \log _{10} M_{0}-1.54
$$

which agrees closely with the empirical formula:

$$
m_{b}=0.22( \pm 0.02) \log _{10} M_{0}+1.85( \pm 0.02)
$$

shown on Figure 8.

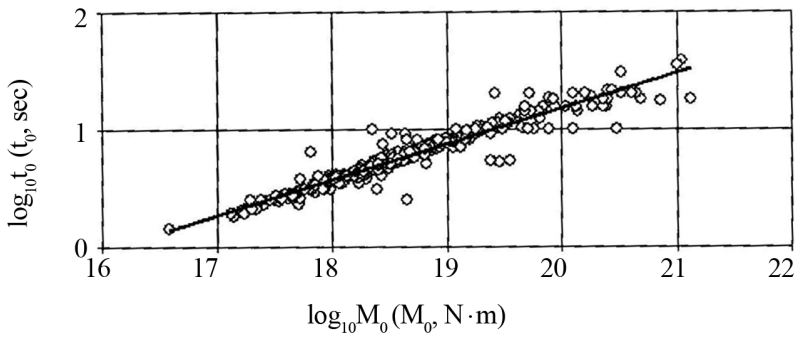

Figure 7. Correlation dependence $\log _{10} t_{0}$ from $\log _{10} M_{0}$ for major earthquakes of the world (1981-1991) by Choy's Catalogue [39]. $\log _{10} t_{0}=0.30( \pm 0.01) \log _{10} M_{0}-4.88( \pm 0.01), N$ $=379, r=0.96$.

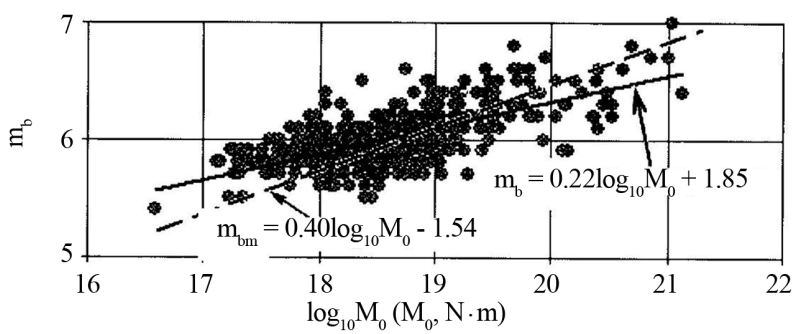

Figure 8. Correlation dependence $m_{b}$ from $\log _{10} M_{0}$ (full line) for major earthquakes of the world (1981-1991) by Choy's Catalogue et al. (1995) for 1981-1991.

$m_{b}=0.22( \pm 0.02) \log _{10} M_{0}-1.85( \pm 0.02), N=362, r=0.67$,

dashed line - calculated dependence:

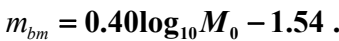


Equation (39) is in good agreement with the dependence on $m_{b}$ from $\log _{10} M_{0}$ for Sumatra island earthquake $\left(\varphi=-10^{\circ}+10^{\circ}, \lambda=+90^{\circ}+100^{\circ}\right.$ ) for 1993-2012 (Figure 9).

Table 1 shows a comparison of the magnitude $\hat{m}_{b}$ obtained by the true maximum amplitude $[19,29,40]$ and the calculated value $m_{b m}$ (Table 1) for a number of large earthquakes in 1960-1984. The presented data suggest that for most of the earthquakes characterized by the following inequality: $\hat{m}_{b} \geq m_{b m}>m_{b}$.

When $\log _{10} \Delta \sigma \geq 7.1$ value of $\hat{m}_{b}$ is close to the $m_{b m}$ same as for Great Chilean earthquake $\hat{m}_{b}=7.57$ and $m_{b m}=7.71$, for Tangshan (1976) $\hat{m}_{b}=6.9$ and $m_{b m}=$ 6.92, Yanyuan (1976). $\hat{m}_{b}=6.5, m_{b m}=6.18$, and if 6.36 $\leq \log _{10} \Delta \sigma<7.0$ value of $\hat{m}_{b}$ more then $m_{b m}$ (Table 1).

Table 2 presents a comparison of calculated $m_{b m}$ and $\hat{m}_{b}$ (21) for 80 major earthquakes of the world for 20002012 for calculations $m_{b m}, \hat{m}_{b}$ and $M_{S m}$ used data from Global CMT Catalogue (Table 2). When comparing $\log _{10} \Delta \sigma$ from Table 1 to Table 2 shows that with increasing $\log _{10} M_{0}$ from 19.15 to 22.72 for the $2000-2012$ earthquakes $\log _{10} \Delta \sigma$ value ranges from 6.75 - 7.58 with an average of 7.16 , that is, much higher than for earthquakes 1960-1984 (Tables 1 and 2) and higher than the standard $\log \Delta \sigma=6.56$.

For such high values $\Delta \sigma$ values $m_{b m}$ closely coincide with the design $\hat{m}_{b}$, and for values $M_{S m}$ characterized by inequality: $M_{S m}>M_{W}$ (Table 2) confirmed that conclusion is the relation $m_{b m}-\hat{m}_{b}$-for earthquakes in Japan and the Kuril Islands $\left(\varphi=30^{\circ}+40^{\circ}, \lambda=140^{\circ}+150^{\circ}\right)$ for the 1993-2012 shown in Figure 10.

Thus for large earthquakes 1960-1984 and 1993-2012 at $\log \Delta \sigma>7.1 m_{b m}$ values coincide closely with the magnitude $\hat{m}_{b}$ calculated from the true maximum amplitude $\left(A_{g}\right)$ of seismic vibrations, the magnitude of which is proportional to the seismic moment: $A_{g} \sim f\left(M_{0}^{0.35}\right)$ to Houston [29] and Kanamori [19]. Consequently, the $m_{b m}$

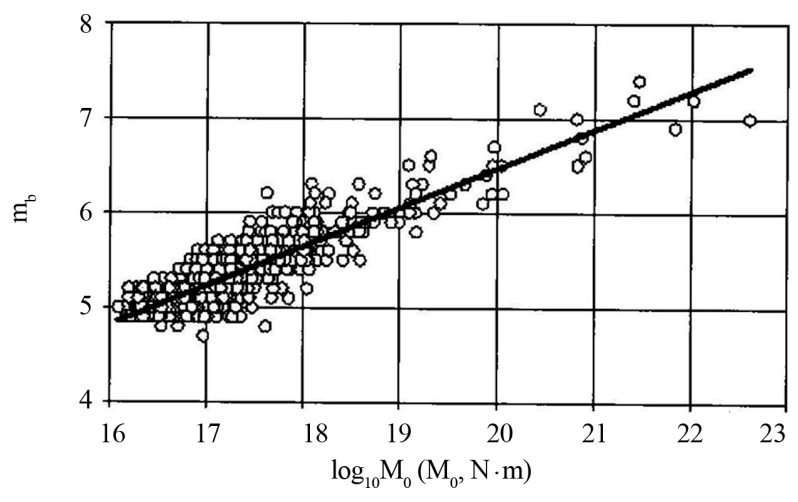

Figure 9. Correlation dependence $m_{b}$ from $\log _{10} M_{0}$ for the earthquakes Sumatra region (1993-2012 years). $m_{b}=0.41( \pm 0.02) \log _{10} M_{0}-1.76( \pm 0.02), N=631, r=0.88$.

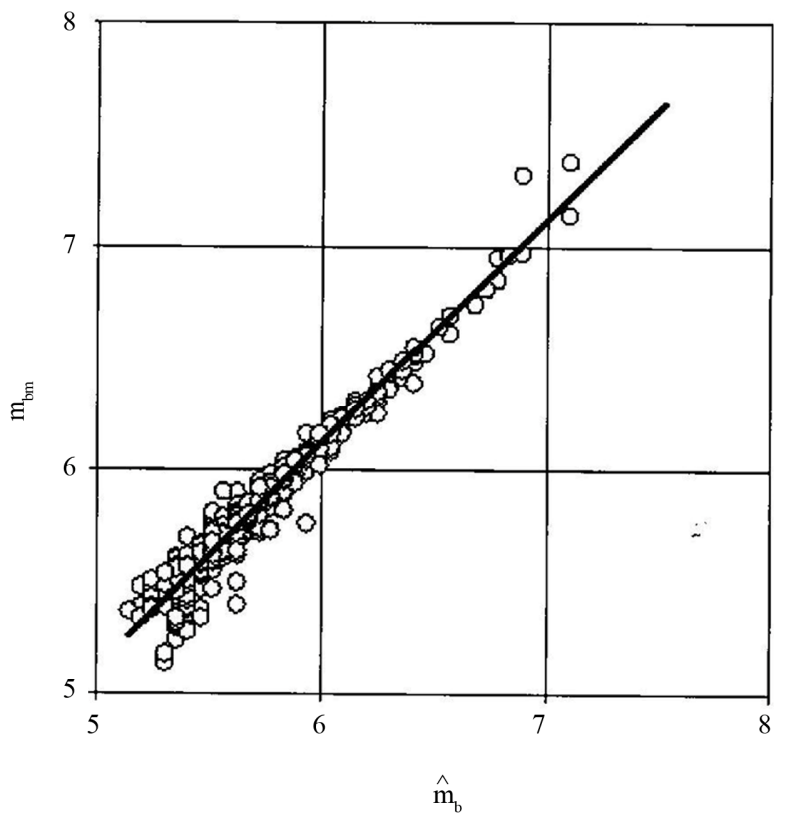

Figure 10. Correlation calculated magnitudes $\boldsymbol{m}_{b m}$ and $\hat{\boldsymbol{m}}_{b}$ for the earthquakes in Japan and Kuril Islands for 19922012 years. $m_{b m}=1.0( \pm 0.02) \hat{m}_{b}+0.14( \pm 0.003), N=521, r$ $=0.97$. Values of $\hat{m}_{b}$ were calculated according to the formula (21).

value is proportional to the $\log _{10} A_{g}$.

The ratio of $M_{S}-\log _{10} M_{0}$. In Mamyrov's papers [18], [28] have shown that in the range of $16 \leq \log _{10} M_{0}<21.0$ if $\log _{10} \Delta \sigma \leq 7.0$ at the rated $M_{S m}$ closely coincides with $\mathrm{M}_{\mathrm{S}}$ and $M_{W}$, and for high $\Delta \sigma \geq 10^{7} \mathrm{~Pa}$ following inequality $M_{S m}>M_{S}$, as shown in Table 2 .

In Figure 11 shows the correlation of $M_{S}$ from $\log _{10} M_{0}$ for earthquakes of the world for 1981-1991 according to the Catalog Chou et al. [39]:

$$
M_{S}=0.73( \pm 0.03) \log _{10} M_{0}-7.47( \pm 0.02)
$$

which is in satisfactory agreement with the dependence $M_{S m}=0.73 \log _{10} M_{0}-7.19$ (Figure 11, dashed line), derived from Equations (38) and (26). These relations with $M_{S}=M_{S m}$ with $\log _{10} M_{0}$ are in good agreement with the generalization of Perez [41] for crustal earthquakes of the world for the years 1950-1997:

$\log _{10} M_{0}=1.33 M_{S}+10.22$.

In Figure 12 shows the correlation $M_{S}$ with $\log _{10} M_{0}$ (solid line) for the earthquakes in Japan and the Kuril Islands in 1993-2012:

$$
M_{S}=0.77( \pm 0.02) \log _{10} M_{0}-8.23( \pm 0.02) \text {, here, we }
$$

show the same relationship

$M_{S m}$ from $\log _{10} M_{0}$ (Figure 12, dashed line):

$M_{S m}=0.69 \log _{10} M_{0}-6.09$, obtained with $(N=521, r$ $=0.99)$ : 
Table 1. A comparison of the magnitude $\hat{m}_{b}$ (Houston, Kanamori, 1986; Zhuo, Kanamori, 1987) and settlement $m_{b m}$ for several major earthquakes of the world.

\begin{tabular}{|c|c|c|c|c|c|c|c|c|c|c|c|c|c|c|c|}
\hline №№ & Date & Time & $\varphi$ & $\lambda$ & $\begin{array}{l}\text { Depth } \\
\mathrm{h}, \mathrm{km}\end{array}$ & $\begin{array}{c}\log _{10} M_{0}, \\
\mathrm{~N}^{*} \mathrm{~m}\end{array}$ & $\begin{array}{l}\log _{10} t_{0} \\
t_{0}, \sec \end{array}$ & $m_{b}$ & $\hat{m}_{b}$ & $m_{b m}$ & $M_{S}$ & $M_{W}$ & $M_{s m}$ & $\begin{array}{c}\log _{10} \Delta \sigma \\
\Delta \sigma, \mathrm{P} a\end{array}$ & Region \\
\hline & 1 & 2 & 3 & 4 & 5 & 6 & 7 & 8 & 9 & 10 & 11 & 12 & 13 & 14 & 15 \\
\hline 1 & $1960 / 5 / 22$ & $19: 11: 17.5$ & -38.29 & -73.05 & 35 & 23.35 & 2.17 & & 7.57 & 7.71 & 8.5 & 9.6 & 9.76 & 7.10 & Great Chilean \\
\hline 2 & $1963 / 10 / 13$ & $5: 17: 55.1$ & 44.76 & 149.80 & 26 & 21.85 & 1.88 & & 7.23 & 6.79 & 8.1 & 8.5 & 8.35 & 6.47 & Great Alaska \\
\hline 3 & $1964 / 3 / 28$ & $3: 36: 12.7$ & 61.02 & -147.63 & 6 & 22.96 & 2.15 & & 7.64 & 7.36 & 8.4 & 9.2 & 9.29 & 6.77 & Rat Island \\
\hline 4 & $1965 / 2 / 4$ & $5: 01: 21.7$ & 51.21 & 178.50 & 29 & 22.15 & 1.94 & & 7.19 & 6.97 & 8.2 & 8.7 & 8.63 & 6.59 & Kurile Isl. \\
\hline 5 & $1967 / 7 / 22$ & $16: 56: 55.3$ & 40.63 & 30.74 & 4 & 20.20 & 1.32 & & 6.38 & 6.26 & 7.1 & 7.4 & 7.28 & 6.50 & Tyrkey \\
\hline 6 & $1968 / 5 / 16$ & $0: 49: 0.4$ & 40.90 & 143.35 & 26 & 21.45 & 1.71 & & 7.18 & 6.73 & 8.1 & 8.3 & 8.16 & 6.58 & Tokachi-oki \\
\hline 7 & $1969 / 8 / 11$ & $21: 27: 37.6$ & 43.48 & 147.82 & 46 & 21.34 & 1.71 & & 6.90 & 6.62 & 7.8 & 8.2 & 8.01 & 6.47 & Kurile Isl. \\
\hline 8 & $1971 / 2 / 9$ & 14:00:41.0 & & & & 19.08 & 0.85 & 6.2 & 6.41 & 6.08 & 6.7 & 6.6 & 6.73 & 6.79 & San Fernando \\
\hline 9 & $1974 / 10 / 3$ & $14: 21: 34.5$ & -12.25 & -77.52 & 36 & 21.18 & 1.65 & & 7.0 & 6.68 & 7.6 & 8.1 & 7.92 & 6.49 & Haicheng, China \\
\hline 10 & $1975 / 2 / 4$ & $11: 36: 7.1$ & 40.67 & 122.65 & 16 & 19.61 & 1.05 & & 6.76 & 6.21 & & 7.0 & 7.03 & 6.72 & Peru \\
\hline 11 & $1976 / 2 / 4$ & $9: 01: 7.2$ & 15.14 & -89.78 & 16.3 & 20.31 & 1.14 & 6.2 & 6.66 & 6.73 & 7.5 & 7.5 & 7.78 & 7.15 & Gua temala \\
\hline 12 & $1976 / 5 / 29$ & $12: 23: 29.9$ & 24.39 & 98.65 & 15 & 19.09 & 0.72 & 6.1 & 6.5 & 6.35 & 6.9 & 6.7 & 7.00 & 7.19 & Longlin, China \\
\hline 13 & $1976 / 5 / 29$ & $14: 00: 33.2$ & 24.29 & 98.58 & 15 & 19.05 & 0.73 & 6.0 & 6.5 & 6.29 & 7.0 & 6.6 & 6.93 & 7.12 & Longlin, China \\
\hline 14 & $1976 / 7 / 27$ & $19: 42: 11.1$ & 39.52 & 118.03 & 15 & 20.44 & 1.11 & 6.3 & 6.9 & 6.92 & 7.9 & 7.6 & 8.01 & 7.37 & Tangshan, China \\
\hline 15 & $1976 / 7 / 28$ & $10: 45: 45.9$ & 39.75 & 118.78 & 15 & 19.55 & 0.88 & 6.3 & 6.7 & 6.49 & 7.4 & 7.0 & 7.29 & 7.47 & Tangshan, China \\
\hline 16 & $1976 / 8 / 16$ & $14: 6: 55.0$ & 32.63 & 104.42 & 15 & 19.11 & 0.73 & 6.1 & 6.9 & 6.35 & 6.9 & 6.7 & 7.01 & 7.18 & Songpan, China \\
\hline 17 & $1976 / 8 / 16$ & $16: 11: 38.7$ & 7.07 & 123.75 & 33 & 21.04 & 1.34 & 6.4 & 7.26 & 7.06 & 7.9 & 8.0 & 8.35 & 7.28 & Mindanao \\
\hline 18 & $1976 / 8 / 21$ & $21: 49: 57.8$ & 32.37 & 104.29 & 15.3 & 18.50 & 0.52 & 6.1 & 6.7 & 6.16 & 6.4 & 6.3 & 6.61 & 7.20 & Songpan China \\
\hline 19 & $1976 / 8 / 23$ & $3: 30: 11.5$ & 32.11 & 104.21 & 19.6 & 18.66 & 0.58 & 6.2 & 6.6 & 6.20 & 6.7 & 6.4 & 6.71 & 7.18 & Songpan China \\
\hline 20 & $1976 / 11 / 6$ & $18: 4: 16.0$ & 27.50 & 101.40 & 22.7 & 18.56 & 0.54 & 5.8 & 6.5 & 6.18 & 6.5 & 6.3 & 6.65 & 7.20 & Yanyuan, China \\
\hline 21 & $1976 / 11 / 15$ & $13: 53: 7.2$ & 39.45 & 117.71 & 15 & 18.63 & 0.56 & 6.0 & 6.3 & 6.21 & 6.3 & 6.4 & 6.71 & 7.21 & Tangshan, China \\
\hline 22 & $1976 / 11 / 24$ & $12: 22: 25.3$ & 38.88 & 43.96 & 15 & 19.62 & 0.90 & 6.1 & 6.58 & 6.52 & 7.3 & 7.0 & 7.34 & 7.16 & Sumbawa \\
\hline 23 & $1977 / 8 / 19$ & $6: 9: 33.1$ & -11.14 & 118.23 & 23.3 & 21.55 & 1.48 & 7.0 & 7.47 & 7.29 & 7.9 & 8.3 & 8.75 & 7.37 & Iran \\
\hline 24 & $1978 / 9 / 16$ & $15: 36: 13.5$ & 33.37 & 57.02 & 11 & 20.12 & 1.34 & 6.5 & 6.9 & 6.14 & 7.4 & 7.3 & 7.13 & 6.36 & Oaxaca \\
\hline 25 & $1978 / 11 / 29$ & $19: 53: 2.9$ & 16.22 & -96.56 & 16.1 & 20.72 & 1.36 & 6.4 & 6.87 & 6.70 & 7.7 & 7.7 & 7.89 & 6.90 & Tyrkey \\
\hline 26 & $1979 / 3 / 14$ & $11: 7: 31.1$ & 17.78 & -101.37 & 26.7 & 20.23 & 1.27 & 6.5 & 6.71 & 6.39 & 7.6 & 7.4 & 7.41 & 6.69 & Petatlan \\
\hline 27 & $1979 / 10 / 15$ & $23: 17: 0.8$ & 32.62 & -115.57 & 12 & 18.86 & 0.78 & 5.7 & 5.92 & 6.00 & 6.9 & 6.5 & 6.57 & 6.78 & Imperial Yalley \\
\hline 28 & $1979 / 12 / 12$ & 8:00:7.0 & 2.32 & -78.81 & 19.7 & 21.23 & 1.35 & 6.4 & 6.91 & 7.23 & 7.7 & 8.1 & 8.58 & 7.44 & Colymbia \\
\hline 29 & $1980 / 1 / 1$ & $16: 42: 49.8$ & 38.80 & -27.74 & 10 & 19.45 & 1.00 & 6.0 & 6.3 & 6.15 & 6.7 & 6.9 & 6.92 & 6.71 & Azores Isl. \\
\hline 30 & $1980 / 2 / 7$ & $10: 49: 26.3$ & -54.29 & 158.43 & 15 & 19.36 & 1.01 & 6.1 & 6.2 & 6.04 & 6.5 & 6.8 & 6.79 & 6.59 & Macguarie Isl. \\
\hline 31 & $1980 / 7 / 17$ & $19: 43: 3.1$ & -12.44 & 165.94 & 34 & 20.68 & 1.24 & 5.8 & 6.79 & 6.90 & 7.9 & 7.8 & 8.07 & 7.22 & Eureka \\
\hline 32 & $1980 / 10 / 10$ & $12625: 25.5$ & 36.14 & 1.41 & 12 & 19.70 & 1.00 & 6.5 & 6.5 & 6.40 & 7.3 & 7.1 & 7.32 & 6.36 & Santa Grus Isl. \\
\hline 33 & $1980 / 11 / 8$ & $10: 27: 45.9$ & 41.14 & -124.36 & 15 & 20.05 & 1.00 & 6.2 & 6.7 & 6.75 & 7.2 & 7.3 & 7.72 & 7.31 & El Asnam, Algeria \\
\hline
\end{tabular}


Continued

\begin{tabular}{|c|c|c|c|c|c|c|c|c|c|c|c|c|c|c|c|}
\hline 34 & $1981 / 1 / 23$ & $21: 13: 55.6$ & 30.86 & 101.35 & 10 & 18.86 & 0.78 & 5.7 & 6.5 & 6.00 & 6.8 & 6.5 & 6.57 & 6.78 & Daofu, China \\
\hline 35 & $1981 / 2 / 24$ & $20: 53: 49.2$ & 38.07 & 23.04 & 10 & 18.95 & 0.78 & 5.9 & 6.6 & 6.09 & 6.7 & 6.6 & 6.69 & 6.97 & Greece \\
\hline 36 & $1981 / 4 / 24$ & $21: 50: 14.3$ & -13.51 & 166.43 & 44.4 & 19.55 & 0.90 & 6.1 & 6.2 & 6.45 & 6.9 & 6.8 & 7.25 & 7.11 & Yanuati Isl. \\
\hline 37 & $1981 / 4 / 27$ & $18: 17: 40.0$ & -57.58 & 147.86 & 10 & 18.91 & 0.78 & 5.7 & 6.1 & 6.05 & 6.5 & 6.5 & 6.64 & 6.83 & Macguarie Isl. \\
\hline 38 & $1981 / 7 / 28$ & $17: 22: 43.6$ & 30.01 & 57.8 & 15.2 & 19.95 & 1.15 & 5.7 & 6.9 & 6.35 & 7.1 & 7.2 & 7.28 & 6.76 & Kurile Isl. \\
\hline 39 & $1991 / 9 / 3$ & $5: 35: 50.1$ & 42.97 & 147.87 & 35.7 & 18.88 & 0.70 & 6.6 & 6.5 & 6.18 & 6.6 & 6.5 & 6.76 & 7.04 & Papua, New Guinea \\
\hline 40 & $1981 / 11 / 6$ & $16: 47: 51$ & -3.18 & 143.72 & 15 & 18.96 & 0.84 & 6.2 & 6.2 & 5.98 & 6.9 & 6.6 & 6.59 & 6.70 & Loayltu Isl. \\
\hline 41 & $1981 / 11 / 24$ & $23: 30: 41.9$ & -22.19 & 170.32 & 23.3 & 19.13 & 0.87 & 5.7 & 6.2 & 6.09 & 6.7 & 6.7 & 6.75 & 6.79 & Kermades Isl. \\
\hline 42 & $1981 / 12 / 24$ & $5: 33: 33.3$ & -29.81 & -177.55 & 19.4 & 19.32 & 1.08 & 6.1 & 6.4 & 5.86 & 6.8 & 6.8 & 6.58 & 6.34 & Iran \\
\hline 43 & $1982 / 8 / 5$ & $20: 33: 2.0$ & -12.52 & 166.01 & 23.9 & 19.50 & 0.98 & 6.2 & 6.3 & 6.24 & 7.1 & 6.9 & 7.02 & 6.82 & Santa Grus Isl. \\
\hline 44 & $1982 / 12 / 19$ & $17: 44: 21.8$ & -24.31 & 175.0 & 29.2 & 20.30 & 1.33 & 6.0 & 6.4 & 6.34 & 7.7 & 7.5 & 7.39 & 6.57 & Tonga Isl. \\
\hline 45 & $1983 / 4 / 3$ & $2: 50: 26.4$ & 8.85 & -83.25 & 28 & 20.26 & 1.27 & 6.5 & 6.6 & 6.42 & 7.2 & 7.4 & 7.52 & 6.71 & Panama \\
\hline 46 & $1983 / 5 / 2$ & $23: 43: 44.7$ & 36.42 & -120.66 & 14.5 & 18.60 & 0.79 & 6.2 & 6.0 & 5.72 & 6.5 & 6.3 & 6.25 & 6.49 & Akito Oki, Japan \\
\hline 47 & $1983 / 5 / 26$ & $3: 0: 18.3$ & 40.44 & 138.87 & 12.6 & 20.66 & 1.30 & 6.8 & 7.2 & 6.76 & 7.7 & 7.7 & 7.93 & 7.02 & Coolinga \\
\hline 48 & $1983 / 10 / 4$ & $18: 52: 37.8$ & -26.01 & -70.56 & 38.7 & 20.53 & 1.46 & 6.4 & 6.8 & 6.31 & 7.3 & 7.6 & 7.50 & 6.41 & Chili \\
\hline 49 & $1983 / 10 / 28$ & $14: 6: 22.5$ & 44.35 & -113.98 & 13.7 & 19.49 & 1.00 & 6.2 & 6.6 & 6.19 & 7.3 & 6.9 & 6.97 & 6.75 & Idaho \\
\hline 50 & $1983 / 11 / 16$ & $16: 13: 5.9$ & 19.40 & -155.59 & 11 & 19.03 & 0.78 & 6.3 & 6.7 & 6.17 & 6.6 & 6.6 & 6.90 & 6.95 & Hawaii \\
\hline 51 & $1983 / 11 / 30$ & $17: 46: 28.9$ & -6.35 & 71.75 & 10 & 20.61 & 1.23 & 6.6 & 7.1 & 6.85 & 7.5 & 7.7 & 8.00 & 7.18 & Chugos Arch \\
\hline 52 & $1984 / 2 / 7$ & $21: 33: 36.1$ & -9.81 & 160.42 & 21.9 & 20.40 & 1.33 & 6.5 & 6.7 & 6.44 & 7.5 & 7.5 & 7.52 & 6.67 & Solomon Isl. \\
\hline 53 & $1984 / 3 / 19$ & $20: 28: 39$ & 40.38 & 63.37 & 15 & 19.55 & 0.78 & 6.5 & 6.7 & 6.69 & 7.0 & 7.0 & 7.49 & 7.47 & Uzbekistan \\
\hline
\end{tabular}

Notice: for the earthquakes N1-10 $\log _{10} t_{0}$ calculated according to $\Delta \sigma$ Kasachara (1984), Purcaru and Berkhemer (1982); for the rest earthquakes N11-52 all data have been taken according to Global CMT Cataloge, for the earthquakes N53- data have been taken from USSR's catalogue, 1984.

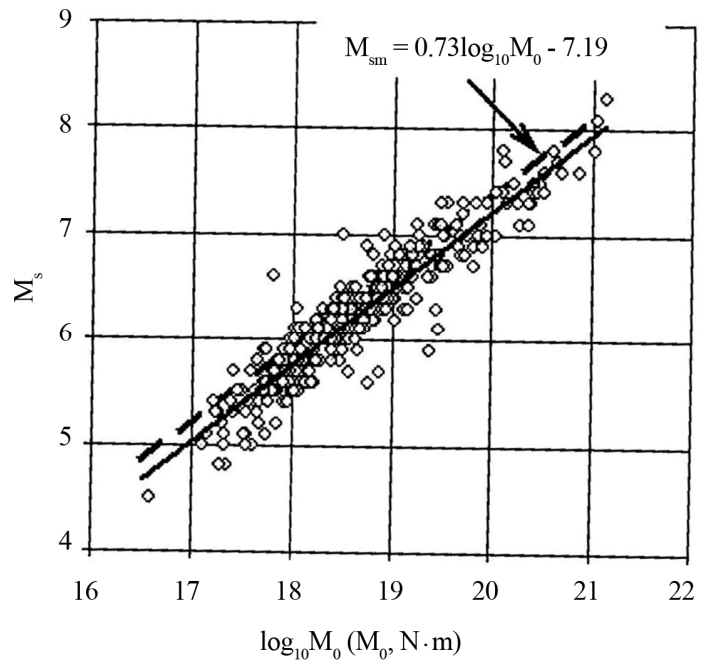

Figure 11. Correlation of magnitudes $M_{S}$ and $\log _{10} M_{0}$ (full line) by Catalogue of major earthquakes of the world Choy [39]: $\quad M_{S}=0.73( \pm 0.03) \log _{10} M_{0}-7.47( \pm 0.02), N=372, r$ $=0.93$. Dashed line - calculated dependence. $M_{S}=0.73 \log _{10} M_{0}-7.19$.

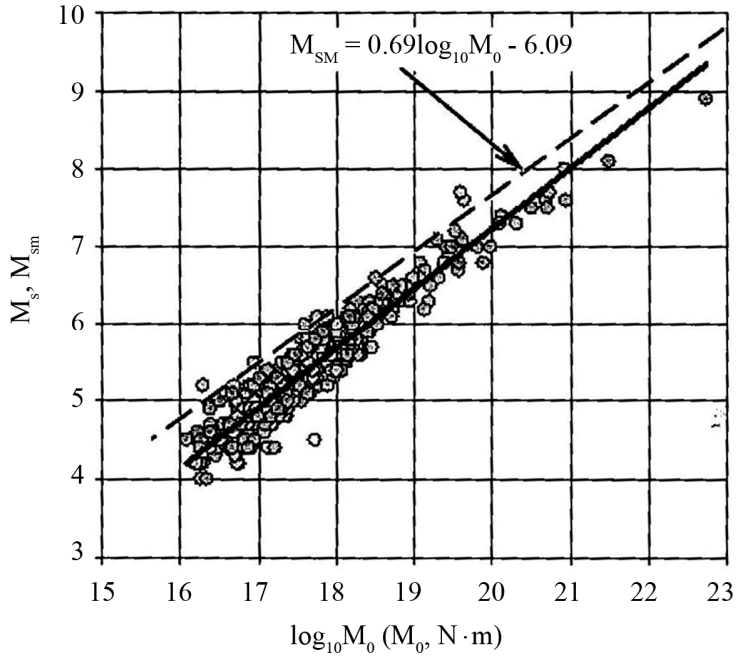

Figure 12. Correlation dependence of magnitude $M_{S}$ from $\log _{10} M_{0}$ for the earthquakes in Japan and Kuril Islands for 1993-2012 years. $M_{S}=0.77( \pm 0.03) \log _{10} M_{0}-8.23( \pm 0.02)$, $N=514, r=0.95$. Dashed line-calculated dependence. $M_{S m}=0.69 \log _{10} M_{0}-6.09$. 
Table 2. Comparison of calculated $\left(m_{b m}, M_{S m}\right)$ and instrumental $\left(m_{b}, M_{S}, M_{W}\right)$ for a number of magnitude large earthquakes of the world 2000-2012 years.

\begin{tabular}{|c|c|c|c|c|c|c|c|c|c|c|c|c|c|c|c|}
\hline №№ & Date & Time & $\varphi$ & $\lambda$ & $\begin{array}{l}\text { Depth } \\
\text { H, км }\end{array}$ & $\begin{array}{l}\log _{10} M_{0} \\
M_{\mathrm{o}}, \mathrm{H}_{\mathrm{M}}\end{array}$ & $\begin{array}{c}\log _{10} t_{0} \\
t_{0}, \mathrm{c}\end{array}$ & $m_{b}$ & $\hat{m}_{b}$ & $m_{b m}$ & $M_{S}$ & $M_{W}$ & $M_{s m}$ & $\begin{array}{c}\log _{10} \Delta \sigma \\
\Delta \sigma, \Pi a\end{array}$ & Region \\
\hline & 1 & 2 & 3 & 4 & 5 & 6 & 7 & 8 & 9 & 10 & 11 & 12 & 13 & 14 & 15 \\
\hline 1 & $2000 / 1 / 8$ & $16: 47: 30.2$ & -16.84 & -173.81 & 162.4 & 19.84 & 0.99 & 6.5 & 6.52 & 6.56 & 6.6 & 7.2 & 7.46 & 7.13 & Tonga Isl. \\
\hline 2 & $2000 / 2 / 25$ & $1: 44: 5.2$ & -19.55 & 174.17 & 16.8 & 19.70 & 0.95 & 6.1 & 6.46 & 6.50 & 7.1 & 7.1 & 7.35 & 7.11 & Vanuatu Isl. \\
\hline 3 & $2000 / 5 / 4$ & $4: 21: 33.4$ & -1.29 & 123.59 & 18.6 & 20.39 & 1.18 & 6.7 & 6.67 & 6.73 & 7.5 & 7.5 & 7.81 & 7.11 & Sulawesi \\
\hline 4 & $2000 / 6 / 4$ & $16: 28: 46.5$ & -4.73 & 101.94 & 43.9 & 20.87 & 1.46 & 6.8 & 6.83 & 6.65 & 8.0 & 7.8 & 7.89 & 6.75 & Sumatra \\
\hline 5 & $2000 / 6 / 18$ & $14: 44: 27.6$ & -13.47 & 97.17 & 15.0 & 20.90 & 1.41 & 6.8 & 6.89 & 6.78 & 7.8 & 7.9 & 8.03 & 6.93 & Indian Ocean \\
\hline 6 & $2000 / 11 / 16$ & $4: 55: 36.5$ & -4.56 & 152.79 & 24.0 & 21.09 & 1.34 & 6.0 & 6.94 & 7.11 & 8.2 & 8.0 & 8.42 & 7.33 & New Ireland \\
\hline 7 & $2000 / 11 / 16$ & $7: 42: 44.5$ & -5.03 & 153.17 & 31.2 & 20.81 & 1.36 & 6.2 & 6.83 & 6.79 & 7.8 & 7.8 & 8.01 & 6.99 & New Ireland \\
\hline 8 & $2000 / 11 / 17$ & $21: 2: 20.1$ & -5.26 & 152.34 & 17.0 & 20.75 & 1.33 & 6.2 & 6.83 & 6.79 & 8.0 & 7.8 & 7.99 & 7.02 & New Britain \\
\hline 9 & $2000 / 12 / 6$ & $17: 11: 14.7$ & 39.60 & 54.87 & 33.0 & 19.59 & 0.94 & 6.7 & 6.41 & 6.41 & 7.5 & 7.0 & 7.22 & 7.03 & Turkmenia \\
\hline 10 & $2001 / 1 / 1$ & $6: 57: 24.0$ & 6.73 & 127.07 & 44.0 & 20.24 & 1.08 & 6.4 & 6.62 & 6.78 & 7.2 & 7.4 & 7.81 & 7.26 & Mindanao \\
\hline 11 & $2001 / 1 / 26$ & $3: 16: 54.9$ & 23.63 & 70.24 & 19.8 & 20.53 & 1.38 & 6.9 & 6.73 & 6.47 & 8.0 & 7.6 & 7.59 & 6.65 & India \\
\hline 12 & $2001 / 6 / 23$ & $20: 34: 23.3$ & -17.28 & -72.71 & 29.6 & 21.67 & 1.63 & 6.7 & 7.15 & 7.11 & 8.2 & 8.4 & 8.61 & 7.04 & Peru \\
\hline 13 & $2001 / 8 / 21$ & $6: 52: 14.3$ & -36.70 & 179.08 & 59.0 & 19.71 & 1.01 & 6.4 & 6.41 & 6.39 & 7.1 & 7.0 & 7.24 & 6.94 & New Zealand \\
\hline 14 & $2001 / 10 / 12$ & $15: 2: 23.3$ & 12.88 & 145.08 & 42.0 & 19.57 & 0.92 & 6.7 & 6.41 & 6.43 & 7.3 & 7.0 & 7.24 & 7.07 & Mariana Isl. \\
\hline 15 & $2002 / 9 / 8$ & $18: 44: 38.3$ & -3.27 & 143.38 & 19.5 & 20.47 & 1.26 & 6.5 & 6.73 & 6.65 & 7.8 & 7.6 & 7.75 & 6.95 & Papua \\
\hline 16 & $2002 / 10 / 10$ & $10: 50: 41.9$ & -1.79 & 134.30 & 15.0 & 20.41 & 1.18 & 6.5 & 6.67 & 6.75 & 7.7 & 7.5 & 7.83 & 7.13 & Java Isl. \\
\hline 17 & $2002 / 11 / 02$ & $1: 26: 25.9$ & 2.65 & 95.99 & 23.0 & 19.95 & 1.09 & 6.2 & 6.52 & 6.47 & 7.6 & 7.2 & 7.40 & 6.94 & Sumatra \\
\hline 18 & $2002 / 11 / 03$ & $22: 13: 28.0$ & 63.23 & -144.89 & 15.0 & 20.87 & 1.37 & 7.0 & 6.83 & 6.83 & 8.5 & 7.8 & 8.07 & 7.02 & Alaska \\
\hline 19 & $2003 / 03 / 17$ & $16: 36: 26.6$ & 51.33 & 177.58 & 27.0 & 19.62 & 0.89 & 5.9 & 6.41 & 6.54 & 6.7 & 7.0 & 7.36 & 7.21 & Aleutian Isl. \\
\hline 20 & $2003 / 08 / 21$ & $12: 12: 59.5$ & -45.01 & 166.87 & 31.8 & 19.87 & 0.98 & 6.6 & 6.52 & 6.61 & 7.5 & 7.2 & 7.52 & 7.19 & New Zealand \\
\hline 21 & $2003 / 09 / 25$ & $19: 50: 38.2$ & 42.21 & 143.84 & 28.2 & 21.48 & 1.52 & 6.9 & 7.10 & 7.14 & 8.1 & 8.3 & 8.58 & 7.18 & Hokkaido \\
\hline 22 & $2003 / 09 / 27$ & $11: 33: 36.2$ & 50.02 & 87.86 & 15.0 & 19.97 & 1.01 & 6.5 & 6.52 & 6.65 & 7.5 & 7.2 & 7.59 & 7.20 & Siberia, Russia \\
\hline 23 & $2004 / 12 / 23$ & $14: 59: 30.9$ & -49.91 & 161.25 & 27.5 & 21.21 & 1.43 & 6.5 & 7.00 & 7.05 & 7.7 & 8.1 & 8.40 & 7.58 & Macquarie Isl. \\
\hline 24 & $2004 / 12 / 26$ & 1:1:9.0 & 3.09 & 94.26 & 28.6 & 22.60 & 1.98 & 7.0 & 7.47 & 7.34 & 8.9 & 9.0 & 9.15 & 6.92 & Sumatra \\
\hline 25 & $2005 / 03 / 28$ & $16: 10: 31.5$ & 1.67 & 97.07 & 25.8 & 22.02 & 1.69 & 7.2 & 7.26 & 7.34 & 8.4 & 8.6 & 8.96 & 7.21 & Sumatra \\
\hline 26 & $2005 / 10 / 08$ & $3: 50: 51.5$ & 34.38 & 73.47 & 12.0 & 20.47 & 1.18 & 6.9 & 6.73 & 6.81 & 7.7 & 7.6 & 7.91 & 7.19 & Pakistan \\
\hline 27 & $2005 / 11 / 14$ & $21: 38: 59.3$ & 38.22 & 144.97 & 18.0 & 19.57 & 0.86 & 6.7 & 6.41 & 6.55 & 6.8 & 7.0 & 7.36 & 7.25 & Honshu \\
\hline 28 & $2006 / 02 / 22$ & $22: 19: 15.0$ & -21.20 & 33.33 & 12.0 & 19.62 & 0.90 & 6.5 & 6.41 & 6.52 & 7.5 & 7.0 & 7.34 & 7.18 & Mozambique \\
\hline 29 & $2006 / 04 / 20$ & $23: 25: 17.6$ & 60.89 & 167.05 & 12.0 & 20.48 & 1.18 & 6.8 & 6.73 & 6.82 & 7.6 & 7.6 & 7.93 & 7.20 & Siberia, Russia \\
\hline 30 & $2006 / 05 / 03$ & $15: 27: 3.7$ & -20.39 & -173.47 & 67.8 & 21.05 & 1.37 & 7.2 & 6.94 & 7.01 & 7.9 & 8.0 & 8.31 & 7.20 & Tonga Isl. \\
\hline 31 & $2006 / 11 / 15$ & $11: 15: 8.0$ & 46.71 & 154.33 & 13.5 & 21.54 & 1.54 & 6.6 & 7.10 & 7.16 & 8.3 & 8.3 & 8.62 & 7.18 & Kuril Isl. \\
\hline 32 & $2007 / 01 / 13$ & $4: 23: 48.1$ & 46.17 & 154.80 & 12.0 & 21.25 & 1.44 & 7.3 & 7.00 & 7.07 & 8.2 & 8.1 & 8.43 & 7.19 & Kuril Isl. \\
\hline 33 & $2007 / 04 / 01$ & $20: 40: 38.9$ & -7.79 & 156.34 & 14.1 & 21.20 & 1.42 & 6.8 & 7.00 & 7.06 & 8.1 & 8.1 & 8.41 & 7.20 & Solomon Isl. \\
\hline 34 & $2007 / 01 / 21$ & 11:28:1.0 & 1.10 & 126.21 & 22.2 & 20.30 & 1.12 & 6.7 & 6.67 & 6.77 & 7.5 & 7.5 & 7.81 & 7.20 & Molucca Sea \\
\hline 35 & $2007 / 08 / 15$ & $23: 41: 57.9$ & -13.73 & -77.04 & 33.8 & 21.05 & 1.37 & 6.7 & 6.94 & 7.01 & 8.0 & 8.0 & 8.31 & 7.20 & Peru \\
\hline 36 & $2007 / 09 / 12$ & 11:11:15.6 & -3.78 & 100.99 & 24.4 & 21.83 & 1.63 & 6.9 & 7.20 & 7.27 & 8.5 & 8.5 & 8.82 & 7.20 & Sumatra \\
\hline 37 & $2007 / 09 / 12$ & $23: 49: 35.3$ & -2.46 & 100.13 & 43.1 & 20.91 & 1.32 & 6.6 & 6.89 & 6.97 & 8.1 & 7.9 & 8.22 & 7.21 & Sumatra \\
\hline 38 & $2007 / 11 / 14$ & $15: 41: 11.2$ & -22.64 & -70.62 & 37.6 & 20.68 & 1.25 & 6.7 & 6.78 & 6.88 & 7.7 & 7.7 & 8.05 & 7.19 & Chile \\
\hline
\end{tabular}




\section{Continued}

\begin{tabular}{|c|c|c|c|c|c|c|c|c|c|c|c|c|c|c|c|}
\hline 39 & $2008 / 10 / 05$ & $15: 53: 1.1$ & 39.50 & 73.64 & 12.0 & 19.15 & 0.73 & 6.4 & 6.25 & 6.59 & 6.9 & 6.7 & 7.06 & 7.22 & Kyrgyzstan \\
\hline 40 & $2008 / 11 / 16$ & $17: 2: 43.8$ & 1.50 & 122.05 & 29.2 & 20.12 & 1.06 & 6.5 & 6.57 & 6.70 & 7.3 & 7.3 & 7.69 & 7.20 & Sulavesi \\
\hline 41 & $2009 / 01 / 03$ & $22: 33: 44.9$ & -0.58 & 133.48 & 18.2 & 20.15 & 1.07 & 6.7 & 6.62 & 6.71 & 7.4 & 7.4 & 7.71 & 7.20 & Java Isl. \\
\hline 42 & $2009 / 01 / 15$ & $17: 49: 48.3$ & 46.97 & 155.39 & 45.2 & 20.18 & 1.08 & 6.9 & 6.62 & 6.72 & 7.5 & 7.4 & 7.73 & 7.20 & Kuril Isl. \\
\hline 43 & $2009 / 05 / 28$ & $8: 25: 4.8$ & 16.50 & -87.17 & 12.0 & 20.11 & 1.05 & 6.7 & 6.57 & 6.71 & 7.3 & 7.3 & 7.70 & 7.22 & Honduras \\
\hline 45 & $2009 / 08 / 10$ & $19: 56: 5.0$ & 14.16 & 92.94 & 22.0 & 20.29 & 1.12 & 6.9 & 6.67 & 6.75 & 7.6 & 7.5 & 7.80 & 7.19 & Andaman Isl. \\
\hline 46 & $2009 / 09 / 02$ & $7: 55: 7.5$ & -8.12 & 107.33 & 53.2 & 19.56 & 0.87 & 6.8 & 6.41 & 6.52 & 7.0 & 7.0 & 7.32 & 7.21 & Java Isl. \\
\hline 47 & $2009 / 09 / 29$ & $17: 48: 26.8$ & -15.13 & -171.97 & 12.0 & 21.22 & 1.43 & 7.1 & 6.99 & 7.06 & 8.1 & 8.1 & 8.41 & 7.19 & Samoa Isl. \\
\hline 48 & $2009 / 09 / 30$ & $10: 16: 17.4$ & -0.79 & 99.67 & 77.8 & 20.44 & 1.17 & 7.1 & 6.73 & 6.8 & 7.5 & 7.6 & 7.89 & 7.19 & Sumatra \\
\hline 49 & $2009 / 10 / 07$ & $22: 3: 28.9$ & -12.59 & 166.27 & 44.2 & 20.51 & 1.19 & 6.4 & 6.73 & 6.83 & 7.7 & 7.6 & 7.95 & 7.20 & Vanuatu Isl. \\
\hline 50 & $2009 / 10 / 07$ & $22: 19: 15.3$ & -11.86 & 166.01 & 41.7 & 20.82 & 1.30 & 6.4 & 6.83 & 6.92 & 7.9 & 7.8 & 8.14 & 7.18 & Santa Crus Isl. \\
\hline 51 & $2009 / 10 / 07$ & $23: 14: 0.6$ & -13.12 & 166.37 & 42.5 & 20.22 & 1.09 & 6.4 & 6.62 & 6.74 & 7.4 & 7.4 & 7.76 & 7.21 & Vanuatu Isl. \\
\hline 52 & $2010 / 01 / 03$ & $22: 36: 42.4$ & -8.88 & 157.21 & 12.0 & 19.76 & 0.94 & 6.4 & 6.46 & 6.58 & 7.1 & 7.1 & 7.45 & 7.20 & Solomon Isl. \\
\hline 53 & $2010 / 02 / 27$ & $6: 35: 14.5$ & -35.98 & -73.15 & 23.2 & 22.27 & 1.78 & 7.2 & 7.36 & 7.41 & 8.3 & 8.8 & 9.11 & 7.19 & Chile \\
\hline 54 & $2010 / 04 / 06$ & $22: 15: 19.1$ & 2.07 & 96.74 & 17.6 & 20.82 & 1.29 & 7.0 & 6.83 & 6.94 & 7.9 & 7.8 & 8.16 & 7.21 & Sumatra \\
\hline 55 & $2010 / 08 / 10$ & $5: 23: 53.9$ & -17.57 & 167.81 & 31.9 & 20.00 & 1.02 & 6.4 & 6.57 & 6.66 & 7.3 & 7.3 & 7.61 & 7.20 & Vanuatu Isl. \\
\hline 56 & $2010 / 10 / 25$ & $14: 42: 59.8$ & -3.71 & 99.32 & 12.0 & 20.83 & 1.30 & 6.5 & 6.83 & 6.93 & 7.8 & 7.8 & 8.15 & 7.19 & Sumatra \\
\hline 57 & $2010 / 12 / 21$ & $17: 19: 53.6$ & 27.10 & 143.76 & 15.6 & 20.24 & 1.10 & 7.0 & 6.62 & 6.74 & 7.5 & 7.4 & 7.77 & 7.20 & Bonin Isl. \\
\hline 58 & $2010 / 12 / 25$ & $13: 16: 51.4$ & -19.67 & 168.04 & 16.6 & 20.05 & 1.04 & 6.8 & 6.57 & 6.67 & 7.4 & 7.3 & 7.64 & 7.19 & Vanuatu Isl. \\
\hline 59 & $2011 / 01 / 02$ & $20: 20: 26.6$ & -38.71 & -73.84 & 19.4 & 19.80 & 0.95 & 6.6 & 6.46 & 6.60 & 7.1 & 7.1 & 7.48 & 7.21 & Chile \\
\hline 62 & $2011 / 03 / 11$ & $5: 47: 32.8$ & 37.52 & 143.05 & 20.0 & 22.72 & 1.84 & 7.2 & 7.52 & 7.74 & 8.9 & 9.1 & 9.59 & 7.46 & Honshu Isl. \\
\hline 63 & 2011/03/11 & $6: 15: 58.7$ & 35.92 & 141.38 & 29.0 & 20.93 & 1.33 & 6.8 & 6.89 & 6.97 & 6.8 & 7.9 & 8.23 & 7.20 & Honshu Isl. \\
\hline 64 & $2011 / 03 / 11$ & $6: 26: 12.6$ & 38.27 & 144.63 & 21.1 & 20.49 & 1.19 & 7.1 & 6.73 & 6.81 & 7.5 & 7.6 & 7.95 & 7.18 & Honshu Isl. \\
\hline 65 & $2011 / 04 / 07$ & $14: 32: 50.6$ & 38.82 & 141.85 & 53.3 & 19.77 & 0.94 & 6.9 & 6.46 & 6.59 & 7.1 & 7.1 & 7.49 & 7.21 & Honshu Isl. \\
\hline 66 & $2011 / 07 / 06$ & $19: 3: 32.5$ & -29.22 & -175.83 & 22.3 & 20.47 & 1.18 & 7.0 & 6.73 & 6.81 & 7.8 & 7.6 & 7.98 & 7.19 & Kermadec Isl. \\
\hline 67 & $2011 / 07 / 10$ & $0: 57: 16.3$ & 37.98 & 143.33 & 22.0 & 19.60 & 0.89 & 6.6 & 6.41 & 6.52 & 7.0 & 7.0 & 7.34 & 7.25 & Honshu Isl. \\
\hline 68 & $2011 / 10 / 23$ & $10: 41: 28.4$ & 38.64 & 43.40 & 12.0 & 19.80 & 0.95 & 6.9 & 6.46 & 6.60 & 7.3 & 7.1 & 7.48 & 7.21 & Turkey \\
\hline 69 & $2012 / 01 / 10$ & $18: 37: 13.3$ & 2.59 & 92.98 & 23.7 & 19.88 & 0.98 & 6.6 & 6.52 & 6.62 & 7.2 & 7.2 & 7.53 & 7.20 & Sumatra \\
\hline 70 & $2012 / 02 / 02$ & $13: 34: 49.2$ & -17.69 & 167.11 & 20.5 & 19.64 & 0.90 & 6.5 & 6.41 & 6.54 & 7.1 & 7.0 & 7.37 & 7.20 & Vanuatu Isl. \\
\hline 71 & $2012 / 03 / 20$ & $18: 2: 54.9$ & 16.60 & -98.39 & 15.4 & 20.30 & 1.12 & 6.6 & 6.67 & 6.76 & 7.6 & 7.5 & 7.81 & 7.20 & Guerrero \\
\hline 72 & $2012 / 03 / 25$ & $22: 37: 20.9$ & -35.31 & -72.41 & 33.8 & 19.78 & 0.94 & 6.5 & 6.46 & 6.60 & 7.1 & 7.1 & 7.48 & 7.22 & Chile \\
\hline 73 & $2012 / 04 / 11$ & $8: 39: 31.4$ & 2.35 & 92.82 & 45.6 & 21.96 & 1.67 & 7.4 & 7.26 & 7.29 & 8.6 & 8.6 & 8.92 & 7.21 & Sumatra \\
\hline 74 & $2012 / 04 / 11$ & $10: 43: 38.2$ & 0.90 & 92.31 & 54.7 & 21.46 & 1.51 & 7.2 & 7.05 & 7.14 & 8.2 & 8.2 & 8.57 & 7.19 & Sumatra \\
\hline 75 & $2012 / 04 / 12$ & $7: 16: 4.6$ & 28.57 & -112.76 & 15.8 & 19.66 & 0.91 & 6.2 & 6.41 & 6.54 & 7.0 & 7.0 & 7.38 & 7.19 & Mexico \\
\hline 76 & $2012 / 08 / 27$ & $4: 37: 38.2$ & 11.91 & -89.18 & 12.0 & 20.07 & 1.04 & 6.5 & 6.57 & 6.69 & 7.3 & 7.3 & 7.66 & 7.21 & Salvador \\
\hline 77 & $2012 / 08 / 31$ & $12: 47: 43.0$ & 11.02 & 127.00 & 46.1 & 20.52 & 1.20 & 6.5 & 6.73 & 6.82 & 7.6 & 7.6 & 7.94 & 7.18 & Philippine \\
\hline 78 & $2012 / 09 / 05$ & $14: 42: 23.7$ & 9.87 & -85.54 & 30.8 & 20.49 & 1.18 & 6.8 & 6.73 & 6.83 & 7.6 & 7.6 & 7.94 & 7.21 & Costa Rica \\
\hline 79 & $2012 / 10 / 28$ & $3: 4: 39.2$ & 52.47 & 132.13 & 15.0 & 20.71 & 1.26 & 6.2 & 6.78 & 6.86 & 7.7 & 7.7 & 8.07 & 7.19 & Charlotte Isl. \\
\hline 80 & $2012 / 11 / 07$ & $16: 35: 55.2$ & 13.93 & -92.47 & 28.7 & 20.11 & 1.06 & 6.6 & 6.57 & 6.69 & 7.4 & 7.3 & 7.68 & 7.19 & Guatemala \\
\hline
\end{tabular}




$$
\log _{10} t_{0}=0.32( \pm 0.003) \log _{10} M_{0}-5.43( \pm 0.003)
$$

From the data that the value $M_{S m}$ an average of 0.5 more than the $M_{S}$, because according to the relation $\log _{10} t_{0}$ with $\log _{10} M_{0}$ (from 42) with growth $\log _{10} M_{0}$ from 16 to 22 on the basis of (19), the value increases from $7.19 \log \Delta \sigma$ to 7.43 (Figure 12), and using equation (38) in the same size ranges of $\log _{10} M_{0}$ the value of $\log _{10} \Delta \sigma$ increases from 6.5 to 7.10 . It is likely that for most crustal earthquakes before 1993 was characterized by the above limits to growth $\log _{10} \Delta \sigma<7.10$.

Ratio $\boldsymbol{m}_{b}-\boldsymbol{M}_{S}$ и $\boldsymbol{m}_{b m}-\boldsymbol{M}_{S m}$. In Figure 13 shows the correlation ratio $m_{b}-M_{S}$ for crustal earthquakes of the Kuril Islands and Japan for 1993-2011:

$$
m_{b}=0.52( \pm 0.03) M_{S}+2.78( \pm 0.02)
$$

which is in good agreement with the expression:

$$
m_{b m}=0.52 M_{S m}+2.74
$$

derived from (42) and (28) for $b_{t}=0.32$ и $a_{t}=-5,43$ (Figure 13).

Figure 14 shows the correlation ratio $m_{b}-M_{S}$ for crustal earthquakes in South America for the years 19932012, $\left(\varphi=-40^{\circ}-0^{\circ}, \lambda=-85^{\circ}-65^{\circ}\right)$ by Global CMT Catalogue:

$$
m_{b}=0.52( \pm 0.03) M_{S}+2.64( \pm 0.02)
$$

for this region was obtained $(N=576, r=0.99)$ :

$$
\log _{10} t_{0}=(0.32 \pm 0.004) \log _{10} M_{0}-5.48( \pm 0.003)
$$

the substitution of which in (26), $b_{t}=0.32$ and $a_{t}=-5.48$ leads to the formula

$$
m_{b m}=0.52 M_{S m}+2.77
$$

Equations (43)-(46) are in good agreement with Equations (21) and (22).

Figure 15 shows the correlation $\log _{10} t_{0}$ of $\log _{10} M_{0}$ for earthquakes of the Tien Shan $\left(\varphi=38.5^{\circ}-45^{\circ}, \lambda=63^{\circ}-\right.$ $\left.96^{\circ}\right)$ for $1960-2012$ in interval $13.0 \leq \log _{10} M_{0} \leq 21.5(N=$ $684, r=0.85)$ :

$$
\log _{10} t_{0}=0.22( \pm 0.01) \log _{10} M_{0}-3.45( \pm 0.01)
$$

which closely coincides with Equations (29), (31) and (36) typical for earthquakes in California (Figures 1 and 15).

Therefore, we can expect that the relationship between magnitudes $m_{b}-M_{S}$ for earthquakes of the two regions may be similar in this range of seismic moment. Indeed, the data in Figure 16 confirmed these assumptions and empirical relationship of $M_{S}$ from $m_{b}$ for Tien Shan's earthquakes is expressed by the following relation $(N=$ $1183, r=0.95$, Figure 16):

$$
M_{S}=1.57( \pm 0.03) m_{b}-3.05( \pm 0.02)
$$

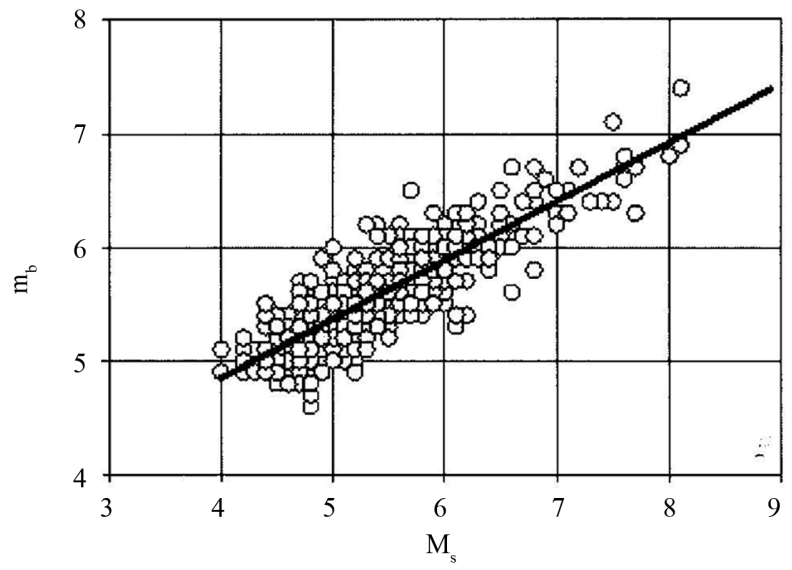

Figure 13. Correlation of magnitudes $m_{b}$ and $M_{S}$ for the earthquakes in Japan and Kuril Islands for 1993-2012 years. $m_{b}=0.52( \pm 0.03) M_{S}+2.78( \pm 0.02), N=514, r=0.84$. Calculated dependence $m_{b m}=0.52 M_{S m}+2.74$ if $\log _{10} t_{0}=0.32 \log _{10} M_{0}-5.43$ (see text).

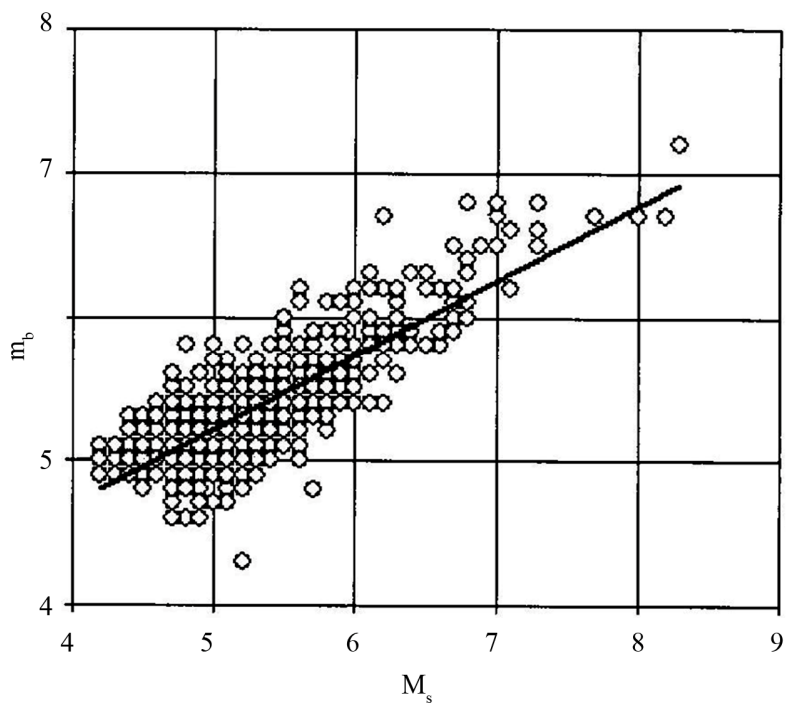

Figure 14. Correlation of magnitudes $m_{b}$ and $M_{S}$ for the earthquakes in South America 1993-2012 years.

$m_{b}=0.52( \pm 0.03) M_{S}-2.64( \pm 0.02), N=547, r=0.82$. Calculated dependence $m_{b m}=0.52 M_{S m}-2.77$ if $\log _{10} t_{0}=0.32 \log _{10} M_{0}-5.48$ (see text).

Calculated dependence of $M_{S m}$ from $m_{b m}$ based on Equations (25), (26) and (47) for the elastic parameters of the standard as follows:

$$
M_{S m}=1.59 m_{b m}-3.06
$$

which is in good agreement with Equations (2), (37) and (49).

Therefore, we have adopted model of the relationship of linear relations between $M\left(m_{b}, M_{L}, M_{S}\right)$ and $\log _{10} t_{0}$ with $\log _{10} M_{0}$ explains many existing empirical formulas. 
For a wide range $6 \leq \log _{10} M_{0} \leq 23$ changing $\log _{10} t_{0}$, to a first approximation, can be described by a nonlinear dependence of $\left(A_{0}=\log _{10} M_{0}\right)$ :

$$
\begin{aligned}
\log _{10} t_{0}= & 0.167 A_{0}-2.83 \\
& +1 / 3 \exp \left(2.166 A_{0}-0.045 A_{0}^{2}-25.09\right)
\end{aligned}
$$

in which the first two terms describes the linear growth $\log _{10} t_{0}$ in the range $6 \leq A_{0} \leq 15$. On the basis of Equations (25)-(27) and (51) in Figure 17 shows estimates nonlinear dependence $m_{b m}, M_{L m}$ and $M_{S m}$ from $M_{W}$ to (11) for crustal earthquakes. From Figure 17 shows that in the



Figure 15. Correlation dependence $\log _{10} t_{0}$ from $\log _{10} M_{0}$ for Tien Shan earthquakes (1960-2012 years).

$\log _{10} t_{0}=0.22( \pm 0.01) \log _{10} M_{0}-3.45( \pm 0.01), N=684, r=$

0.85.

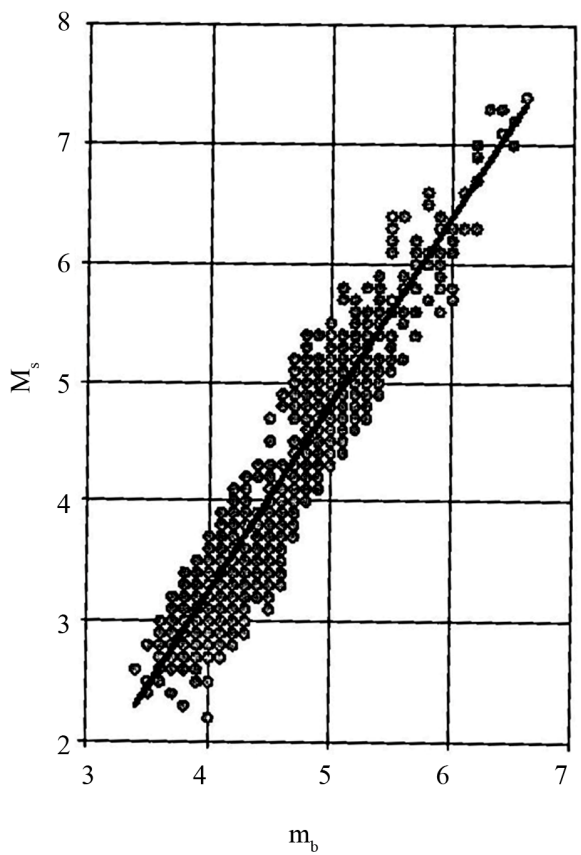

Figure 16. Correlation of magnitudes $M_{S}$ and $m_{b}$ for Tien Shan earthquakes (1902-2012 years).

$M_{S}=1.57( \pm 0.03) m_{b}-3.05( \pm 0.02), N=1183, r=0.95$.

Calculated dependence $M_{S m}=1.59 m_{b m}-3.06$ if

$\log _{10} t_{0}=0.22 \log _{10} M_{0}-3.45$ (see the text).



Figure 17. Averaged according $M_{S m} M_{L m}$ and $m_{b m}$ from $M_{W}$ for crustal earthquakes (see text), the dashed line represents the intersection of the curves $M_{S m} \approx M_{L m} \approx m_{b m} \approx M_{W} \approx 5.26$ $-\mathbf{5 . 5 0}$.

interval $4 \leq M_{W} \leq 6,5$ numerical values of magnitudes $m_{b m} \approx m_{b}, M_{L m} \approx M_{L}, M_{S m} \approx M_{S}$ and $M_{W}$ within the accuracy of these parameters are close. In accordance with Equations (19) and (51) in the interval $6.0<A \leq 23.0$ $\log _{10} \Delta \sigma$ value increases from 1.75 to 7.53 , and the most intense increase in this parameter is in the range $6.0 \leq A_{0}$ $\leq 15.0$.

\section{Conclusions}

1) A broad range of local Richter magnitude $M_{L}, \mathrm{~m}_{\mathrm{b}}$, and $M_{S}$ crustal earthquakes in different regions shows a possible functional relationship with the seismic moment magnitude, corner frequency, voltage and depressurized seismic elastic parameters of the geophysical environment. These links justify numerous empirical relationships with magnitudes of seismic moment.

2) It is assumed that an upgraded body-wave magnitude $m_{b m}$ for large earthquakes is proportional to the logarithm of the average displacement along the fault $\log _{10} u, \hat{m}_{b}$, the true magnitude and the maximum amplitude of seismic vibrations $A_{g}$; magnitude $M_{S m}$ is proportional to the logarithm of the square average displacement along the fault $\left(2 \log _{10} u\right)$ and local magnitude proportional $1.5 \log _{10} u$.

3) Control parameters of the quantitative relations with seismic moment magnitudes are coefficients depending on the change in corner period of seismic stress drop or discharged from the seismic moment, which provide a self-consistent system of equations between the main source parameters of crustal earthquakes. 


\section{REFERENCES}

[1] B. Gutenberg, "Amplitudes of P, PP, an S waves and Magnitude of Shallow Earthquakes," Bulletin of the Seismological Society of America, Vol. 35, No. 2, 1945, pp. 57-69.

[2] B. Gutenberg and C. F. Richter, "Earthquake Magnitude, Intensity, Energy and Acceleration," Bulletin of the Seismological Society of America, Vol. 46, No. 2, 1956, pp. 105-145.

[3] B. Gutenberg and C. F. Richter, "Magnitude and Energy of Earthquakes," Annali di Geofisica, Vol. 9, No. 1, 1956, pp. 1-15.

[4] N. V. Kondorskaya, A. I. Zakharova and L. S. Chepkunas, "The Quantitative Characteristics of Earthquake Sources as Determined in the Seismological Practice of the U.S.S. R.," Tectonophysics, Vol. 166, No. 1-3, 1989, pp. 45-52. doi:10.1016/0040-1951(89)90204-7

[5] T. G. Rautian, "Energy of Earthquakes," In: Y. V. Riznichenko, Ed., Methods for the Detailed Study of Seismicity, Akademii Nauk SSSR, Moscow, 1960, pp. 75-114.

[6] T. G. Rautian, V. J. Khalturin, K. Fujita, K. G. Mackey, et al., "Origins and Methodology of the Russian Energy K-Class System and Its Relationship to Magnitude Scales," Seismological Research Letters, Vol. 78, No. 6, 2007, pp. 579-590. doi:10.1785/gssrl.78.6.579

[7] P. Chen and H. Chen, "Scaling Law and Its Applications to Earthquake Statistical Relations," Tectonophysics, Vol. 166, No. 1-3, 1989, pp. 53-72.

doi:10.1016/0040-1951(89)90205-9

[8] L. B. Grant, "Paleoseismology, International Handbook of Earthquake and Engineering Seismology, Part A," Academic Press, Waltham, 2002.

[9] A. A. Gusev and V. N. Melnikova, "Relations between Magnitudes: Global and Kamchatka Data," Volkanology and Seismology, Vol. 6, 1990, pp. 55-63.

[10] K. Kasahara, "Earthquake Mechanics," 1985.

[11] P. Mai and G. C. Beroza, "Source Scaling Potpies from Finite-Fault-Rupture Models," Bulletin of the Seismological Society of America, Vol. 90, No. 3, 2000, pp. 604615. doi: $10.1785 / 0119990126$

[12] O. W. Nuttli, "Average Seismic Source-Parameters Relation for Mid-Plate Earthquakes," Bulletin of the Seismological Society of America, Vol. 73, No. 2, 1983, pp. 519535.

[13] K. Aki, "Generation and Propagation of G-Waves from the Niigata Earthquake of June 16, 1964. Part 2. Estimation of Earthquake Moment, Released Energy, and StressStrain Drop from the G-Wave Spectrum," Bulletin of the Earthquake Research Institute, Tokyo, 1966.

[14] K. Aki and P. A. Richards, "Quantitative Seismology. Theory and Methods, v. t., Moskau: Mir," 1983.

[15] J. N. Brune, "Tectonic Stress and the Spectra of Seismic Shear Waves from Earthquakes," Journal of Geophysical Research, Vol. 75, No. 26, 1970, pp. 4997-5009. doi:10.1029/JB075i026p04997

[16] V. Keilis-Borok, "On Estimation of the Displacement in an Earthquake Source and Dimension," Annales Geo- physicae, Vol. 12, No. 1-4, 1959, pp. 205-214.

[17] P. Debye, "Zur Theorie der Spezifischen Wärmen," Annalen der Physik, Vol. 344, No. 14, 1912, pp. 789-839. doi:10.1002/andp.19123441404

[18] E. Mamyrov, "Relations among Earthquake Source Parameters Derived from Debye Solid-Body Model," Journal of Geodynamics, Vol. 22, No. 1, 1996, pp. 137-143. doi:10.1016/0264-3707(96)00005-1

[19] H. Kanamori, "The Energy Released in Great Earthquakes," Journal of Geophysical Research, Vol. 82, No. 20, 1977, pp. 2981-2987. doi:10.1029/JB082i020p02981

[20] G. A. Bollinger, M. C. Chapman and M. S. Sibol, "A Compassion of Earthquake Damage Areas a Function of Magnitude across the United States," Bulletin of the Seismological Society of America, Vol. 83, 1993, pp. 1064 1080 .

[21] D. M. Boore, "The Richter Scale: Its Development and Use for Determining Earthquake Source Parameters," Tectonophysics, Vol. 166, 1989, pp. 1-14. doi:10.1016/0040-1951(89)90200-X

[22] T. S. Hanks and D. M. Boore, "Moment-Magnitude Relations in Theory and Practice," Journal of Geophysical Research, Vol. 89, No. B7, 1984, pp. 6229-6235. doi:10.1029/JB089iB07p06229

[23] E. M. Scordilis, "Empirical Global Relations Converting $\mathrm{M}_{\mathrm{S}}$ and $\mathrm{m}_{\theta}$ to Moment Magnitude," Journal of Seismology, Vol. 10, 2006, pp. 225-236. doi:10.1007/s10950-006-9012-4

[24] T. Utsu, "Relationships between Magnitude Scales, International Handbook of Earthquake and Engineering Seismology, Part A," Academic Press, Waltham, 2002.

[25] C. F. Richter, "An Instrumental Earthquake Magnitude Scale," Bulletin of the Seismological Society of America, Vol. 25, No. 1, 1935, pp. 1-32.

[26] N. I. Christensen, "Poisson's Ratio and Crustal Seismology," Journal of Geophysical Research, Vol. 101, No. B2, 1996, pp. 3139-3156. doi:10.1029/95JB03446

[27] N. I. Christensen and W. D. Mooney, "Seismic Velocity Structure and Composition of the Continental Crust: A Global View," Journal of Geophysical Research, Vol. 100, No. B6, 1995, pp. 9761-9788. doi:10.1029/95JB00259

[28] E. Mamyrov, "New System of Quantitative Correlations between Seismic Energy, Magnitude and Energy of Seismic Radiation of the Crust Earthquakes in Tien Shan," The 33rd General Assembly of the European Seismological Commission, Moscow, 19-24 August 2012, pp. 29-30.

[29] H. Houston and H. Kanamori, "Source Spectra of Great Earthquakes: Teleseismic Constraints on Rupture Process and Strong Motion," Bulletin of the Seismological Society of America, Vol. 76, No. 1, 1986, pp. 19-42.

[30] W. Thatcher and C. Hahks, "Source Parameters of Southern California Earthquakes," Journal of Geophysical Research, Vol. 78, No. 35, 1973, pp. 8547-8575. doi:10.1029/JB078i035p08547

[31] K. K. Zapolskii, J. L. Nersesov, T. G. Rautian and V. I. Halturin, "Physical Basis of Magnitude Classification of Earthquakes," 1974.

[32] F. Scherbaum and D. Stoll, "Source Parameters and Scal- 
ing Laws of the 1978 Schwabian Jura (Southwest Germany) Aftershocks," Bulletin of the Seismological Society of America, Vol. 73, No. 5, 1983, pp. 1321-1343.

[33] A. Jin, C. A. Moya and M. Ando, "Simultaneous Determination of Site Responses and Source Parameters of Small Earthquakes along the Atotsugawa Fault Zone, Central Japan," Bulletin of the Seismological Society of America, Vol. 90, No. 6, 2000, pp. 1430-1445. doi:10.1785/0119990140

[34] H. S. Hasegawa, "Lg-Spectra of Local Earthquake Recorder by the Eastern Canada Telemeters Network and Spectral Scaling," Bulletin of the Seismological Society of America, Vol. 73, 1983, pp. 1041-1061.

[35] G. Grunthal and R. Wahlstrom, "An $M_{W}$ Based Earthquake Catalogue for Central, Northern and North-Western Europe Using a Hierarchy of Magnitude Conversions," Journal of Seismology, Vol. 7, No. 4, 2003, pp. 507-531. doi:10.1023/B:JOSE.0000005715.87363.13

[36] J. G. Ristau, G. C. Rogers and F. Cassidy, "Moment Magnitude-Local Magnitude Calibration for Earthquake in Western Canada," Bulletin of the Seismological Society of America, Vol. 95, No. 5, 2005, pp. 1994-2000. doi: $10.1785 / 0120050028$
[37] J. Ristau, "Comparison of Magnitude Estimates for New Zealand Earthquakes: Moment Magnitude, Local Magnitude, and Teleseismic Body-Wave Magnitude," Bulletin of the Seismological Society of America, Vol. 99, No. 3, 2009, pp. 1841-1852. doi:10.1785/0120080237

[38] Y. M. Wu, R. M. Allen and C. W. Wu, "Revised M $\mathrm{L}_{\mathrm{L}}$ Determination for Crustal Earthquake in Taiwan," Bulletin of the Seismological Society of America, Vol. 95, No. 6, 2005, pp. 2517-2524. doi:10.1785/0120050043

[39] G. L. Choy and J. Boatwright, "Global Patterns of Radiated Seismic Energy and Apparent Stress," Journal of Geophysical Research, Vol. 100, No. B9, 1995, 1820518228. doi:10.1029/95JB01969

[40] Y. Zhuo and H. Kanamori, "Regional Variation of the Short-Period (1 to 10 Second) Source Spectrum," Bulletin of the Seismological Society of America, Vol. 77, No. 2, 1987, pp. 514-529.

[41] O. J. Perez, "Revised World Seismicity Catalog (19501997) for Strong $\left(M_{S} \geq 6\right)$ Shallow $(h \leq 70 \mathrm{~km})$ Earthquakes," Bulletin of the Seismological Society of America, Vol. 89, No. 2, 1999, 335-341. 